\title{
Article \\ Electrical Aircraft Ship Integrated Secure and Traverse System Design and Key Characteristics Analysis
}

\author{
Zhuxin Zhang ${ }^{1,2,3}$, Qian Liu ${ }^{1,2,4, * \mathbb{C}}$, Dingxuan Zhao ${ }^{1,2,4}$, Lixin Wang ${ }^{1,2,4}$ and Tuo Jia ${ }^{1,2,3}$ \\ 1 Research Center of Special Carrier Equipment, Yanshan University, Qinhuangdao 066004, China; \\ zhzhxn@ysu.edu.cn (Z.Z.); zdx@ysu.edu.cn (D.Z.); wlx@stumail.ysu.edu.cn (L.W.); jiatuo@ysu.edu.cn (T.J.) \\ 2 Key Lab of Special Carrier Equipment of Hebei Province, Yanshan University, Qinhuangdao 066004, China \\ 3 School of Vehicle and Energy, Yanshan University, Qinhuangdao 066004, China \\ 4 School of Mechanical Engineering, Yanshan University, Qinhuangdao 066004, China \\ * Correspondence: 1q_ysu@stumail.ysu.edu.cn
}

check for updates

Citation: Zhang, Z.; Liu, Q.; Zhao, D.; Wang, L.; Jia, T. Electrical Aircraft Ship Integrated Secure and Traverse System Design and Key

Characteristics Analysis. Appl. Sci. 2022, 12, 2603. https://doi.org/ 10.3390/app12052603

Academic Editor: Zhi-Ting Ye

Received: 27 January 2022

Accepted: 1 March 2022

Published: 2 March 2022

Publisher's Note: MDPI stays neutral with regard to jurisdictional claims in published maps and institutional affiliations.

Copyright: () 2022 by the authors. Licensee MDPI, Basel, Switzerland. This article is an open access article distributed under the terms and conditions of the Creative Commons Attribution (CC BY) license (https:/ / creativecommons.org/licenses/by/ $4.0 /)$.
Featured Application: The research results of this paper are mainly applied to the landing assistance of the shipborne helicopter, including the capture and traction of the shipborne helicopter after landing.

\begin{abstract}
The shipborne helicopter is an essential maritime combat force of the modern navy. However, as the most advanced shipborne helicopter landing assistance system, the ASIST still suffers from the significant disadvantage of the uncontrollable driving speed of the claw. This paper aims to propose an implementation scheme of the EASIST transmission system by selecting an asynchronous motor as the direct power source to solve the problem. On this basis, the speed controller is built by combining the vector control algorithm with an ANFIS control algorithm. In addition, the capture and traction characteristics of EASIST are analyzed, and the capture track of the claw and the maximum load in the traction process are obtained. Finally, the dynamics model of the transmission system is established by power bond graph theory, and the system simulation test is carried out. Simulation results show that the proposed EASIST reduces the capture time by about $60 \%$ and dramatically reduces the capture speed. And when towing the shipborne helicopter, EASIST can keep a good speed-tracking effect under the action of wildly varying load force. The research results of this paper are of great significance to broaden the application scope of ASIST and improve the traction efficiency, which plays a vital role in enhancing the combat effectiveness of shipborne helicopters.
\end{abstract}

Keywords: shipborne helicopter; capture; traction; ANFIS; power bond graph

\section{Introduction}

Shipborne helicopters refer to helicopters that can land on aircraft carriers or other ships. Shipborne helicopters have played an indispensable role in modern naval warfare since the 21st-century [1-3] with the reform of modern warfare and the wide application of new UAVs (Unmanned Aerial Vehicles). In modern naval warfare, shipborne helicopters are required to land not only on aircraft carriers but also on medium-sized and small ships. Unlike aircraft carriers, the rolling and pitching range of medium-sized and small ships is large, and the area of the landing platform on the ships is small. These problems make the landing difficulty of shipborne helicopters increase exponentially [4,5].

Various schemes have been introduced since 1971 to improve the landing ability of shipborne helicopters on medium-sized and small ships, ensure the attendance rate in high sea conditions, and enhance safety and reliability. The shipborne helicopter landing assistance system, considered adequate and widely used, includes Harpoon Assist Landing System, Recovery Assist Secure and Traverse System, and Aircraft Ship Integrated Secure and Traverse System (ASIST). ASIST, as the third-generation shipborne helicopter landing 
assistance system, is considered the development direction in the future with its unique design scheme and excellent functional characteristics [6,7].

As shown in Figure 1, according to the landing action of the shipborne helicopter and the task execution sequence of ASIST, the process can be divided into five stages [6].

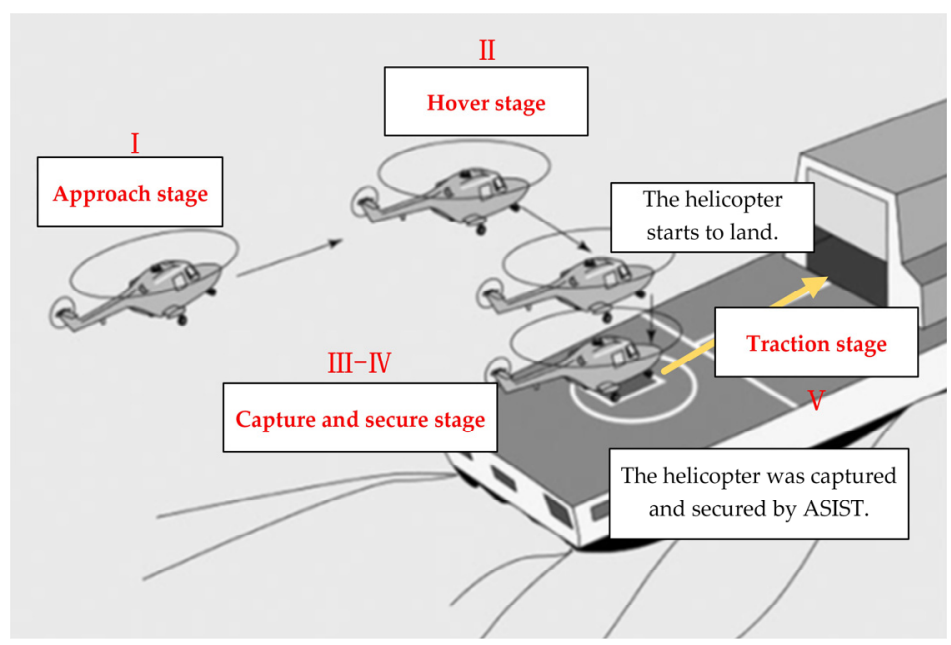

Figure 1. The five landing stages of helicopters.

- $\quad$ Approach stage: The shipborne helicopter approaches the ship from a distance.

- Hover stage: The shipborne helicopter hovers above the deck.

- Capture stage: The shipborne helicopter is captured by ASIST.

- $\quad$ Secure stage: The shipborne helicopter is secured to the deck by ASIST.

- Traction stage: The shipborne helicopter is towed to the designated position by ASIST.

Many scholars have researched the different landing stages, which involve aerodynamics, structural dynamics, system reliability, speed trajectory planning, traction path planning, and many other aspects.

In the approach stage, Greer et al. [8] studied the task of the shipborne helicopter approaching the ship and proposed an approach guidance method.

In the hover stage, Yu et al. [9-11] thoroughly studied the influence of airflow between the shipborne helicopter and the deck. Shi et al. [12] further investigated the effect of the interaction between the shipborne helicopter and the deck when two shipborne helicopters hover over the deck simultaneously.

In the secure stage, Li et al. $[13,14]$ studied the collision process between the tire and the deck when the shipborne helicopter landed on the ship and established the corresponding collision model. Zhao et al. [15] evaluated the secure reliability of the shipborne helicopter through the analytic hierarchy process. Wang et al. $[16,17]$ studied the ship-helicopter dynamic system and showed the dynamic model.

However, few studies have been conducted on the capture and traction stage of the shipborne helicopter, or few people have paid attention to the problems of large impact force and the cumbersome traction process existing in ASIST [6]. The former made the ASIST incompatible with small shipborne aircraft, while the latter made the traction operation inefficient. It is imperative to seek a more reasonable, cleaner, and environmentally friendly design scheme based on the original ASIST to solve the deficiencies existing in ASIST [18,19].

Because asynchronous motors have the advantages of high power-density, highenergy transmission efficiency, and strong environmental adaptability [20,21], they are very suitable for the ship environment where ASIST is located. It is very convenient to use the asynchronous motor as the power source of ASIST with an appropriate speed control algorithm to solve the above problems. However, the asynchronous motor itself is a high-order, nonlinear, time-varying system with strong coupling, and the longitudinal load 
of the motor is time varying during the working process of the ASIST system, which makes it difficult for the conventional PID controller to achieve a better control effect. With the development of intelligent control technology, more and more intelligent controllers have been designed and used for motor control in recent years. Among them, Adaptive Networkbased Fuzzy Inference System (ANFIS) has both the powerful knowledge expression ability of Fuzzy control and the self-learning ability of Neural Network, which effectively solves the control problems of complex, uncertain systems [22-24]. The ANFIS controller has been applied in the DC motor field, and it has been proved that the ANFIS controller has significant advantages over the traditional PID controller [25-28]. Because of the above reasons, this paper uses the ANFIS controller as the speed controller of the asynchronous motor and combines it with the vector control algorithm to get a better speed control effect.

Power bond graph theory is a system dynamics modeling method proposed by American Professor H. M. Paynter in the early 1960s [29]. After years of development and improvement, it has been applied in various research fields, especially in electromechanical integration systems [30-34]. This method can precisely extract the critical parameters according to the characteristics, which helps obtain the system state equation more intuitively [35-38]. Therefore, it is always used to establish the dynamic model of the transmission system.

In this paper, firstly, the working conditions of ASIST are analyzed. The asynchronous motor was selected as the power source, and an implementation scheme of Electrical Aircraft Ship Integrated Secure and Traverse System (EASIST) transmission system was proposed. On this basis, the key characteristics of EASIST are analyzed, and the capture trajectory planning is carried out. The maximum force of EASIST in the traction stage is also obtained by force analysis. Finally, the dynamic model of the transmission system is established by power bond graph theory, and the simulation test is carried out.

The results show that EASIST can reduce the capture time and capture speed while keeping the applied sea conditions unchanged, and the ANFIS controller has a good speed control effect when towing the helicopter. The research results of this paper make ASIST compatible with small shipborne aircraft and are of great significance to improve traction efficiency. More importantly, the all-electric transmission scheme of EASIST will be cleaner and more environmentally friendly.

\section{Working Conditions Analysis of ASIST}

\subsection{Introduction to Working Principle}

ASIST is mainly composed of the Main Power Unit (MPU), Light Indicator, Laser Sources, Camera, Probe Rod, Rapid Secure Device (RSD), and Track and Main Controller. Figure 2 shows the composition diagram of the ASIST system. According to the different working stages, the working principle of ASIST can be described as follows:

\section{Approach stage}

After receiving the landing instruction, the helicopter approaches the ship according to the obtained ship position information. The laser sources installed on both sides are collected by the camera installed on the deck when the helicopter reaches the upper part of the ship deck. The position of the helicopter relative to the ship is calculated in real time. The light indicator then guides the helicopter to the designated landing area.

\section{Hover stage}

The helicopter hovers over the landing area as directed by the light indicator, waiting for landing instructions.

\section{Capture stage}

The helicopter starts to land when the external environment meets the capture requirements. RSD moves forward rapidly, driven by the MPU, and captures the helicopter's probe rod by the claw installed on the RSD when the helicopter tires contact the deck. 
4. Secure stage

The MPU and RSD work together to lock the helicopter to the deck after the claw captures the probe rod. If necessary, this process will be assisted by the ropes.

5. Traction stage

The operator controls MPU and RSD to tow the helicopter to the desired position when the external environment meets the traction requirements.

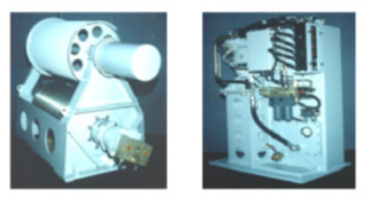

1-MPU

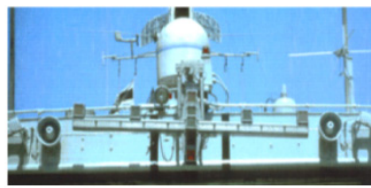

2-Light indicator

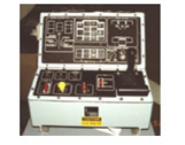

8-Main controller

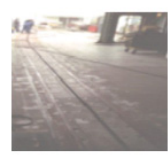

7-Track

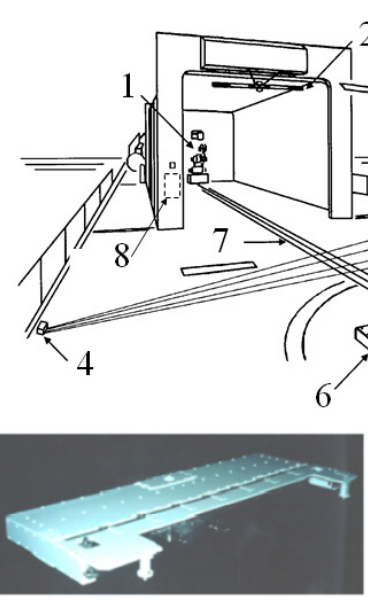

6-RSD

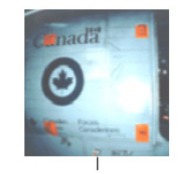

3-Laser sources

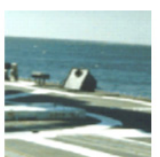

4-Camera

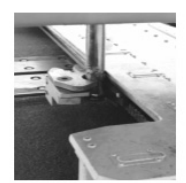

5-Probe rod

Figure 2. Composition diagram of ASIST [6].

\subsection{Working Conditions Analysis}

According to the working principles of ASIST, the primary actuators of the system, including MPU and RSD, mainly undertake the following tasks:

1. Capture stage

Once the helicopter lands on the deck, the ASIST needs to capture the probe rod as quickly as possible to avoid sideshow or rollover accidents. MPU and RSD need to complete the capture actions within no more than $1.5 \mathrm{~s}[6,39]$, including MPU driving RSD to capture the probe rod longitudinal and RSD driving the claw to capture the probe rod lateral, as shown in Figure 3.
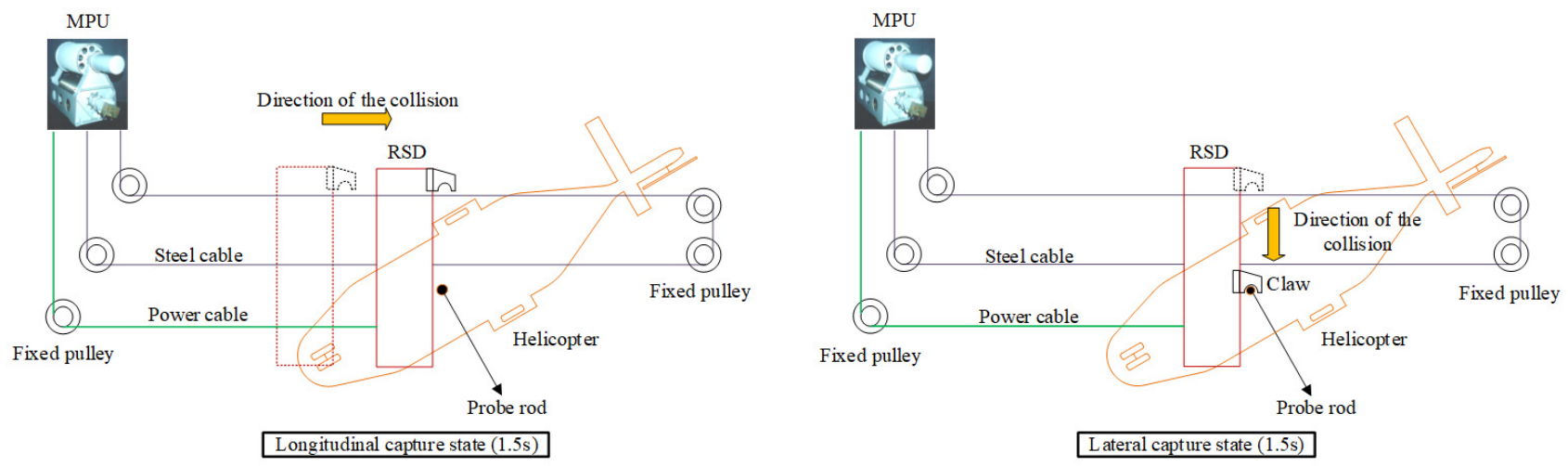

Figure 3. Capture stage diagram. 


\section{Traction stage}

The MPU and RSD are required to tow the helicopter to the specified position under maximum level-3 sea conditions, including the MPU longitudinal towing the helicopter along the deck and the RSD lateral towing the helicopter, as shown in Figure 4.
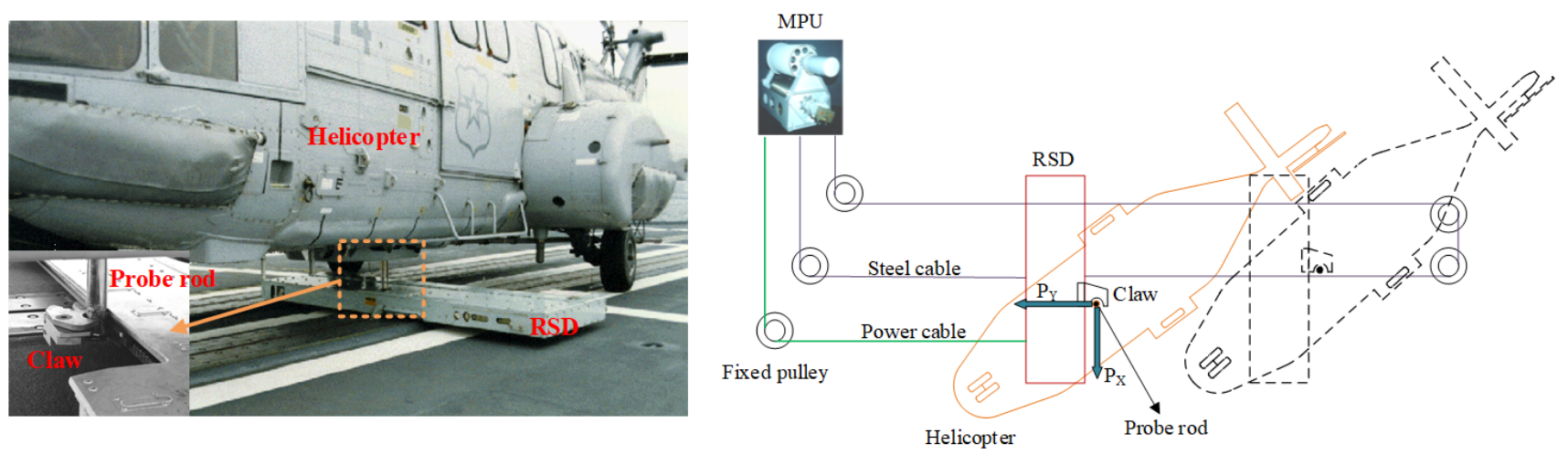

Figure 4. Traction stage diagram.

As we can see, MPU and RSD play a significant role in the whole process. However, due to the limitation of technical conditions in design, both the longitudinal and lateral speed of the claw cannot be regulated, which leads to the following two problems that are difficult to solve.

- In the capture stage

The impact force between the claw and the probe rod is enormous, making ASIST unable to assist the landing of small shipborne aircraft.

- In the traction stage

The position and attitude of the helicopter must be adjusted repeatedly because the traction speed is not controllable. This process takes a long time, the operation steps are complex, and the operator must be highly experienced.

Therefore, it is urgent to design an improved ASIST to solve the above-mentioned problems. EASIST, which uses an asynchronous motor as the power source, has become the preferred solution due to its energy-saving characteristics, cleanness, low noise, high power density, and convenient speed regulation.

\section{Design of the EASIST Transmission System}

\subsection{The Actuators}

\subsubsection{EMPU}

The primary transmission system of EMPU is shown in Figure 5. The basic working principle is as follows:

The asynchronous motor drives the steel cable reel to rotate through the reducer and pulls ERSD along the longitudinal through the steel cable. The steel cable reel also rotates the power cable reel through the chain so that the power cable can move following ERSD. In this process, the EMPU controller controls the speed of the asynchronous motor. The system regulates steel cable tension through the hydraulic cylinders mounted on the fixed pulley.

\subsubsection{ERSD}

The primary transmission system of ERSD is shown in Figure 6. The basic working principle is as follows: 


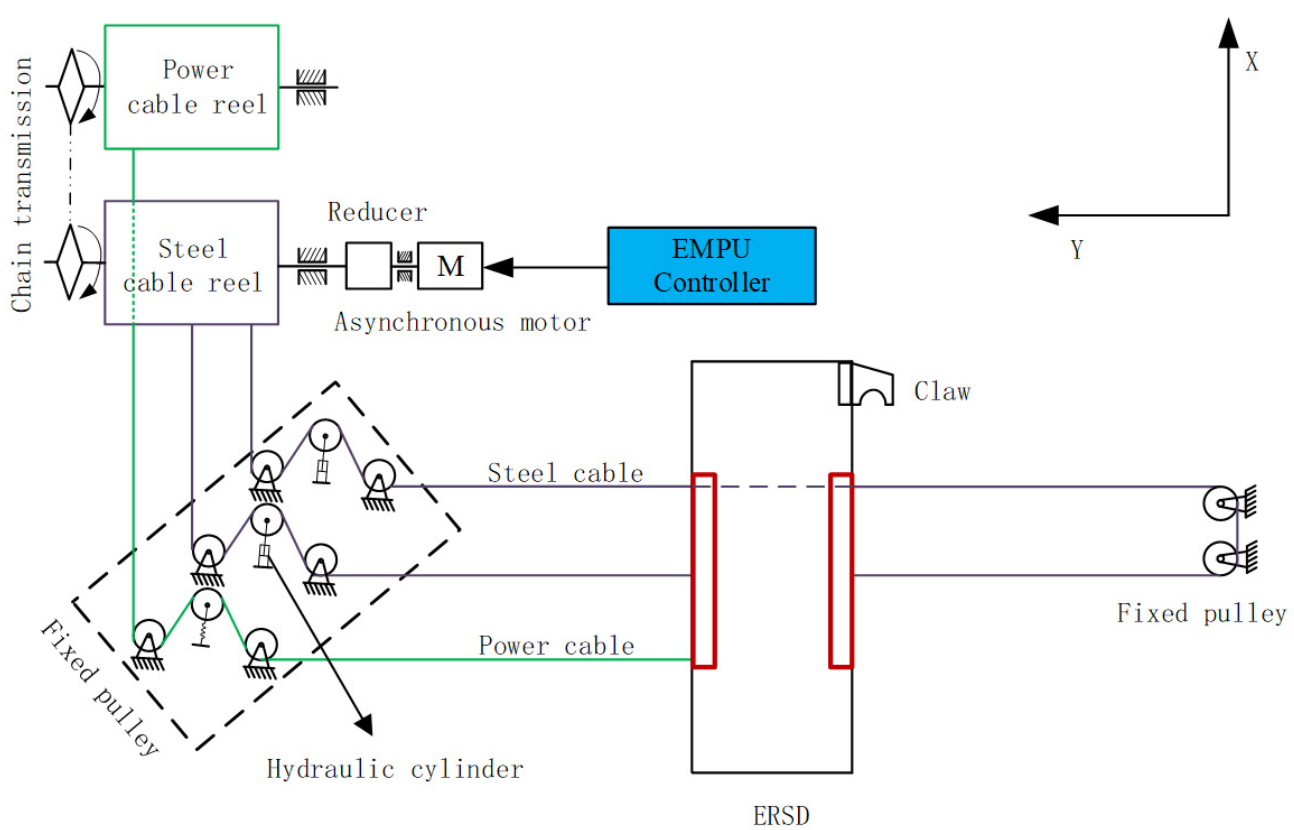

Figure 5. Schematic diagram of EMPU transmission system.

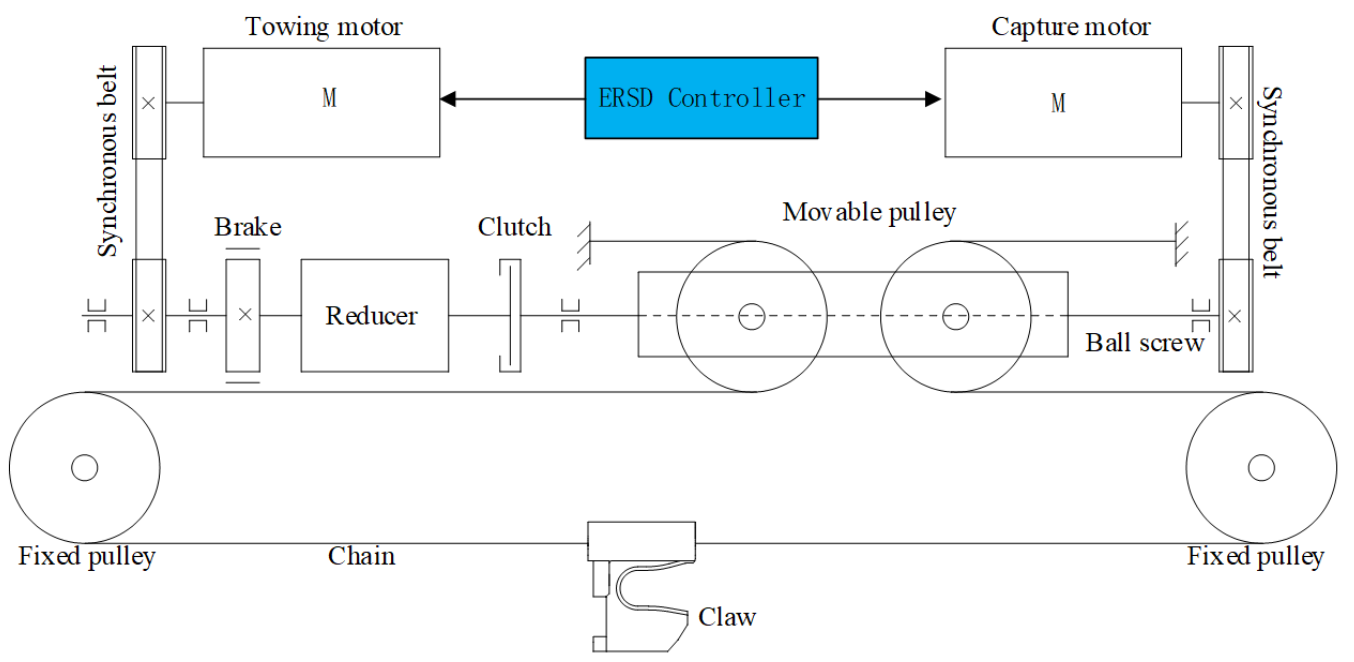

Figure 6. Schematic diagram of ERSD transmission system.

The traction task: the towing motor drives the movable pulley assembly to move through the reducer and ball screw and then transforms into the slow lateral movement of the claw through the chain drive mechanism.

The capture task: the capture motor drives the movable pulley to move directly through the ball screw, which is then converted into the rapid lateral movement of the claw. In the process of traction and capture, the ERSD controller controls the speed of two motors.

\subsection{The Controller}

The control system is designed by combining the ANFIS control algorithm with the vector control algorithm to make EASIST have a good speed control effect under complex working conditions. The control system could adjust the PID parameters according to the field working state in real time. The control system structure is shown in Figure 7. 

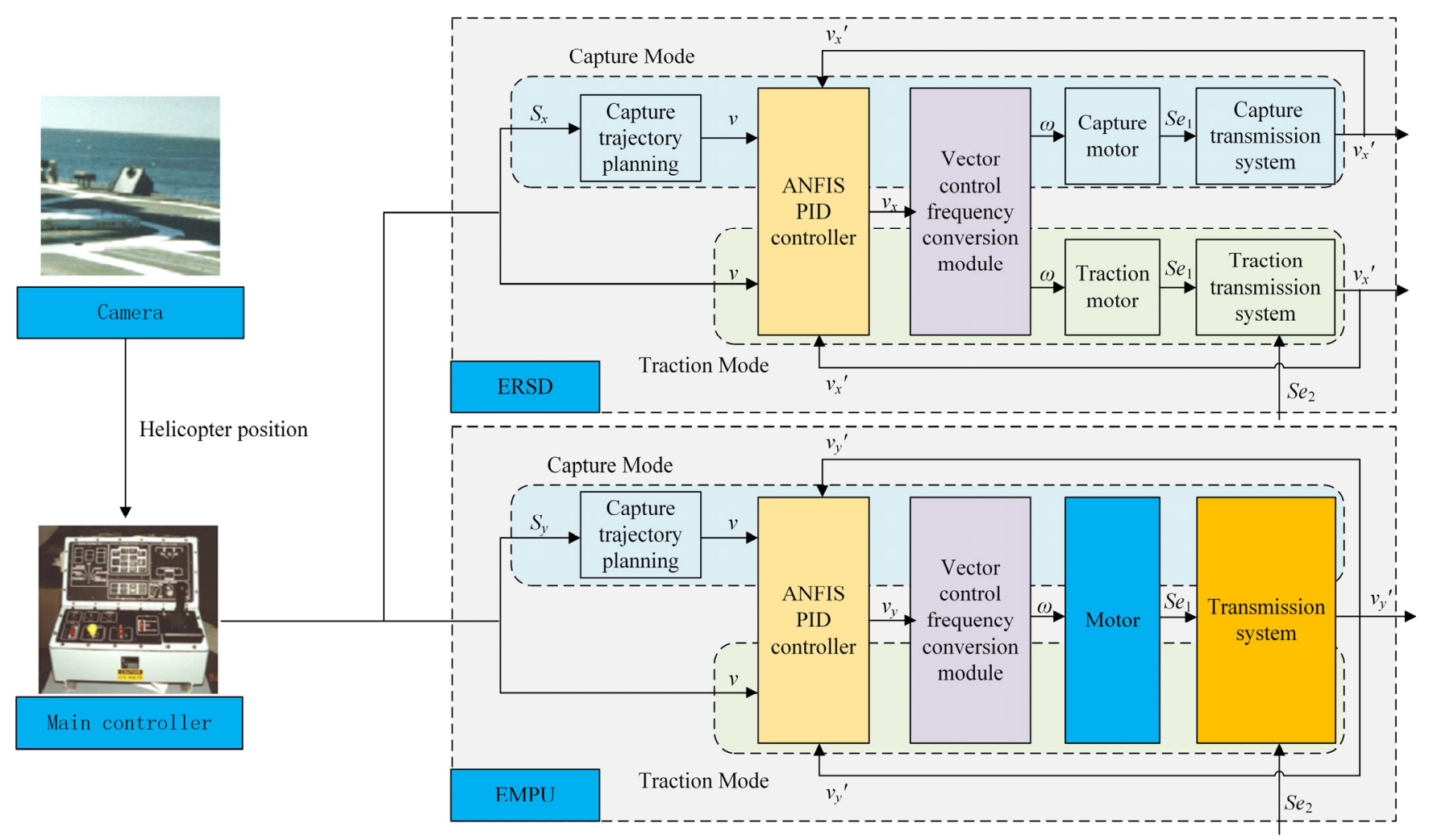

Figure 7. Structure diagram of the control system.

\subsubsection{ANFIS PID Controller}

The RBF neural network, first proposed by J. Moody et al., is a local approximation network, which can approximate any nonlinear function with any accuracy and has the significant advantage of fast learning speed [40]. This paper designs the ANFIS controller by combining it with Fuzzy. The controller structure is shown in Figure 8, which consists of four layers: input layer, fuzzy layer, fuzzy reasoning layer, and output layer [41].

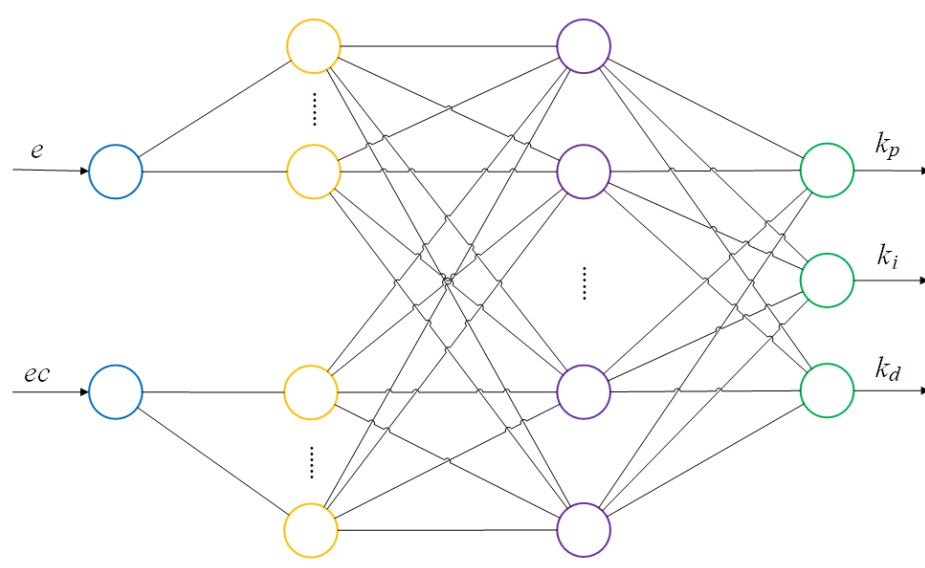

Input layer Fuzzy layer Fuzzy reasoning layer Output layer

Figure 8. ANFIS PID control system structure.

The input layer includes $e$ and $e c$. The second layers describe the premise module IF in fuzzy rules. The third layer corresponds to the fuzzy reasoning module. And the output 
layer is $k_{p}, k_{i}$ and $k_{d}$ variables. The configuration of ANFIS is 2-14-49-3. The input variables $e$ and $e c$ are blurred into $E, E C$ and divided into fuzzy subsets of the following form:

$$
\begin{aligned}
E & =\{\mathrm{NB}, \mathrm{NM}, \mathrm{NS}, \mathrm{ZO}, \mathrm{PS}, \mathrm{PM}, \mathrm{PN}\}, \\
E C & =\{\mathrm{NB}, \mathrm{NM}, \mathrm{NS}, \mathrm{ZO}, \mathrm{PS}, \mathrm{PM}, \mathrm{PN}\} .
\end{aligned}
$$

- The first layer: the input layer.

The input quantity is imported into the ANFIS, and the input variables of this layer are $e$ and $e c$.

$$
\left\{\begin{array}{l}
x_{1}=e(t) \\
x_{2}=e c(t) \\
O_{1}(i)=\left[x_{1}, x_{2}\right]
\end{array}\right.
$$

where $i=1,2$.

- $\quad$ The second layer: the fuzzy layer.

The function of this layer is to fuzzy the input variables and calculate the membership function of each input variable. There are 14 nodes in this layer, corresponding to $E$ and EC language variables: NB, NM, NS, ZO, PS, PM, and PN. This layer corresponds to the premise of the fuzzy rule, which is the IF part.

$$
O_{2}(i, j)=\exp \left(\frac{-\left[O_{1}(i)-C_{i j}\right]^{2}}{\left(b_{i j}\right)^{2}}\right)
$$

where $i=1,2 ; j=1,2, \ldots, 7$.

- $\quad$ The third layer: the fuzzy reasoning layer.

The function of this layer is to describe the fuzzy rules and form the fuzzy reasoning decisions. According to the input variables number and fuzzy subsets of each variable, the number of nodes in this layer is 49 . Each node represents a fuzzy rule. The output of this layer corresponds to the conclusion of the fuzzy rules, which is the THEN part.

$$
\mathrm{O}_{3}(i)=\mathrm{O}_{2}\left(1, k_{1}\right) \mathrm{O}_{2}\left(2, k_{2}\right)
$$

where $k_{1}=1,2, \ldots, 7 ; k_{2}=1,2, \ldots, 7 ; i=1,2, \ldots, 49$.

- The fourth layer: the output layer.

The function of this layer is to defuzzify. The results obtained by the previous layer are weighted and output to the PID controller. The output variables are the setting results of $k_{p}, k_{i}$, and $k_{d}$.

$$
O_{4}(i)=\sum_{j=1}^{9} O_{3}(j) \omega_{i j}
$$

where $i=1,2,3$.

$$
\left\{\begin{array}{l}
O_{4}(1)=k_{p} \\
O_{4}(2)=k_{i} \\
O_{4}(3)=k_{d}
\end{array}\right.
$$

- Learning algorithm.

The system objective function is

$$
E(k)=\frac{1}{2} \sum_{k}\left(t_{k}-p_{k}\right) .
$$

where $t_{k}$ is the expected output of neuron $k, p_{k}$ is the actual output of neuron $k$. 
The center $c_{i j}$ and width $b_{i j}$ of the Gaussian function of ANFIS, and the weight $w_{i j}$ between the fuzzy reasoning layer and output layer adopt a gradient descent method.

$$
\begin{aligned}
\Delta c_{i j} & =\eta \frac{\partial E(k)}{\partial c_{i j}}+\alpha \Delta c_{i j} \\
\Delta b_{t j} & =\eta \frac{\partial E(k)}{\partial b_{i j}}+\alpha \Delta b_{i j} \\
\Delta \omega_{i j} & =\eta \frac{\partial E(k)}{\partial \omega_{i j}}+\alpha \Delta \omega_{i j}
\end{aligned}
$$

where $\eta$ is the learning efficiency, $\alpha$ is the inertia coefficient.

\subsubsection{Vector-Controlled Converter}

According to the principle of vector control, as shown in Figure 9, the current in the three-phase coordinate system of the asynchronous motor is equivalent to the current in the two-phase static coordinate system. And the two-phase static coordinate system is equal to the two-phase synchronous rotating coordinate system through coordinate transformation. If the coordinate system is rotated simultaneously with the core of the asynchronous motor, the DC motor model can be obtained; that is, the three-phase asynchronous AC motor is equivalent to the DC motor.

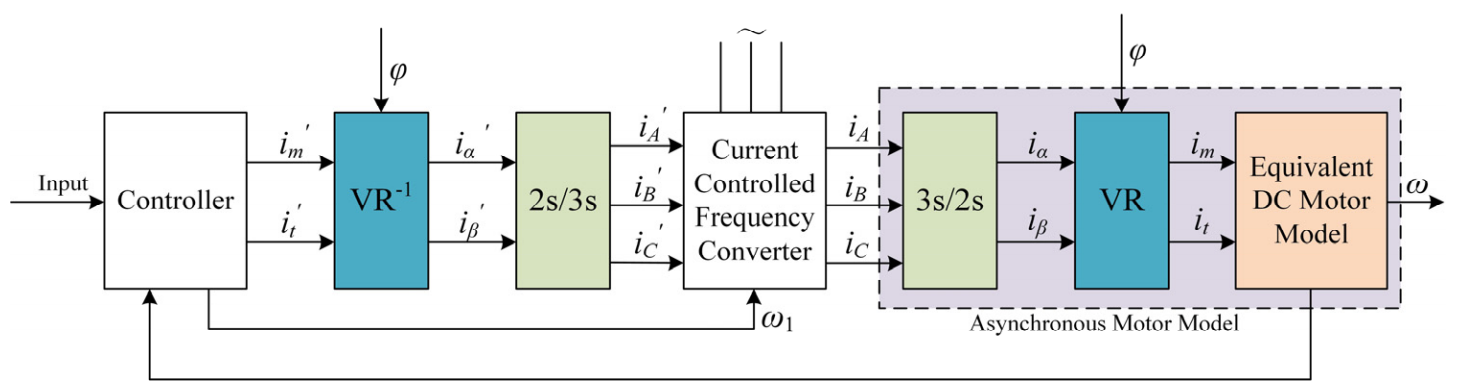

Figure 9. Schematic diagram of the vector control system [42].

In Figure 9, the corresponding $\mathrm{VR}^{-1}-\mathrm{VR}$ and $2 \mathrm{~s} / 3 \mathrm{~s}-3 \mathrm{~s} / 2 \mathrm{~s}$ cancel each other so that the input signal can be directly equivalent to the frequency signal of the motor. On this basis, when the two-phase synchronous rotating coordinate system is oriented according to the rotor flux, the mathematical model of the asynchronous motor can be obtained as follows [42,43]:

$$
\left\{\begin{array}{l}
\psi_{r}=\frac{L_{m}}{T_{r} p+1} i_{s m} \\
\omega_{s}=\omega_{1}-\omega=\frac{L_{m} i_{s t}}{T_{r} \psi_{r}} \\
T_{e}=\frac{n_{p} L_{m}}{L_{r}} i_{s t} \psi_{r}
\end{array}\right.
$$

where

- $\quad \Psi_{r}$ is rotor flux;

- $\quad i_{s m}, i_{s t}$ are stator current;

- $\quad L_{r}, L_{m}$ are rotor inductance and stator/rotor mutual inductance;

- $\quad R_{r}$ is rotor resistance, $L_{r}$ is rotor inductance, $T_{r}=L_{r} / R_{r}$;

- $\quad p$ is the differential operator;

- $\quad \omega_{\mathrm{s}}$ is the angular velocity of the coordinate axis d-q relative to the rotor;

- $\quad \omega_{1}$ is the angular velocity of the coordinate axis d-q relative to the stator;

- $\quad \omega$ is the rotor angular velocity of the asynchronous motor;

- $\quad n_{p}$ is the polar logarithm;

- $\quad T_{e}$ is the motor torque [42]. 


\section{Key Characteristics Analysis}

\subsection{Capture Characteristic}

Since EASIST can accurately control the motor speed, it is possible to merge the capture processes of EMPU and ERSD, as shown in Figure 10. ERSD immediately drives the claw to approach the probe rod along the lateral when EMPU starts driving the ERSD to approach the probe rod along the longitudinal. Thus, the total capture time can be reduced by more than half.
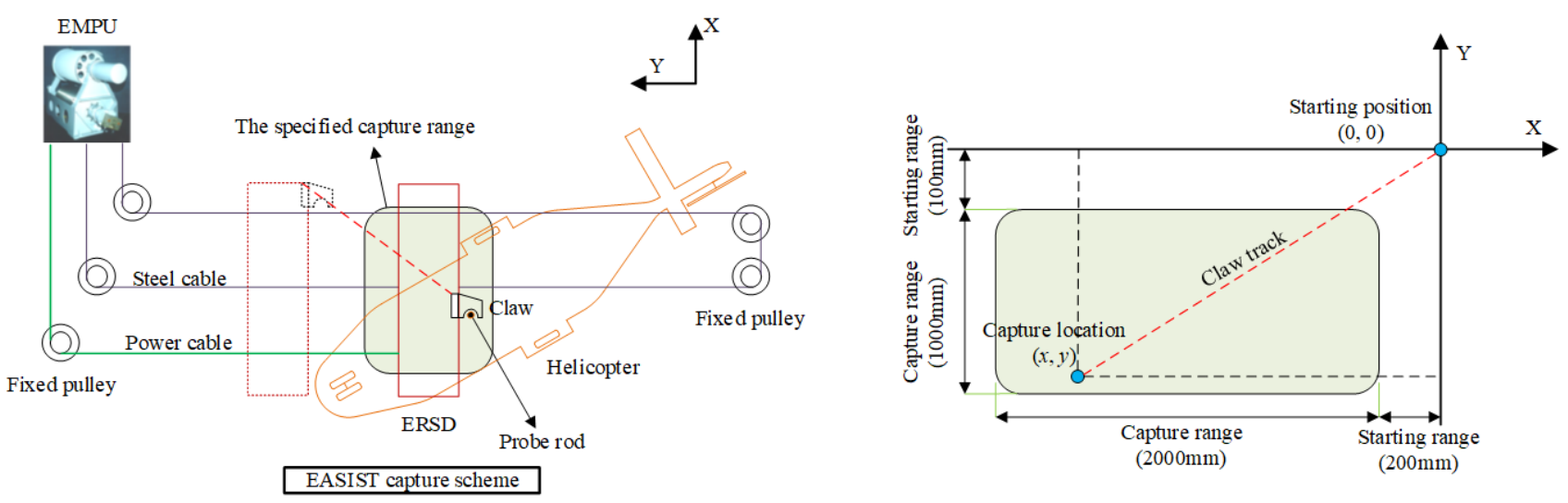

Figure 10. EASIST capture stage diagram.

The driving speed trajectory of EMPU and ERSD needs to be planned to minimize the capture time and reduce the capture force. Both EMPU and ERSD have the following characteristics when executing a capture task:

- The claw displacement is determined.

- The claw accelerates from rest.

- The claw impacts the probe rod at a low speed.

For example, the capture process of EMPU can be described as follows. As shown in Figure 11, EMPU drives ERSD to start from rest and accelerates flexibly to a certain speed $v_{\max }$ and runs at this speed uniformly for a fixed displacement. EMPU enters the deceleration stage and decelerates to $v$ in the remaining distance when ERSD approaches the probe rod. At the same time, it reaches the end of the displacement and completes the longitudinal capture task.

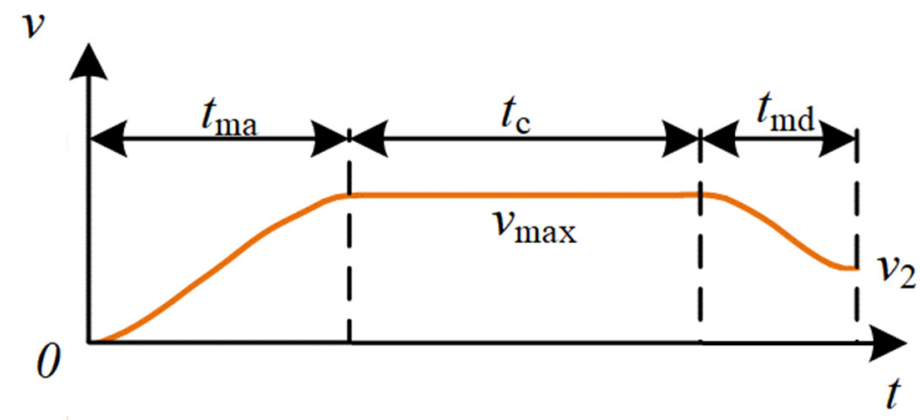

Figure 11. Velocity curve planning [42].

In the motor control system, a suitable trajectory planning algorithm is helpful to reduce mechanical wear, increase the service life, and improve the control accuracy of the system. Compared with other trajectory planning algorithms, the cosine function has advantages of the smooth connection point, infinite continuous derivative, and simple 
calculation $[42,44,45]$. The cosine function is used to construct the longitudinal capture velocity trajectory as follows:

$$
\begin{cases}v_{\mathrm{ya}}(t)=\frac{1}{2} v_{\max }\left(1-\cos t_{\mathrm{a}}^{\prime}\right) & 0 \leq t<t_{\mathrm{ma}} \\ v_{\mathrm{yc}}(t)=v_{\max } & t_{\mathrm{ma}} \leq t<t_{\mathrm{ma}}+t_{\mathrm{c}} \\ v_{\mathrm{yd}}(t)=\frac{1}{2}\left(v_{\max }+v_{2}\right)-\frac{1}{2}\left(v_{2}-v_{\max }\right) \cos t_{\mathrm{d}}^{\prime} & t_{\mathrm{ma}}+t_{\mathrm{c}} \leq t\end{cases}
$$

where

- $\quad t_{a}^{\prime}=\left(t / t_{\mathrm{ma}}\right) \pi, t_{d}^{\prime}=\left[\left(t-t_{\mathrm{ma}}-t_{c}\right) / t_{\mathrm{md}}\right] \pi ;$

- $\quad t_{\mathrm{ma}}$ is the required time of acceleration;

- $\quad t_{\mathrm{md}}$ is the required time of deceleration;

- $\quad t_{\mathrm{c}}$ is the time of constant velocity.

And the lateral capture velocity can be structured by normalizing the longitudinal speed according to the position of the probe rod [45], as shown below:

$$
v_{x}=\lambda v_{y} .
$$

For the position $(x, y)$ of the probe rod at the time of capture, the normalization factor $\lambda$, can be obtained from the following equation:

$$
\lambda=\frac{x}{y} .
$$

\subsection{Traction Characteristic}

EMPU and ERSD will be subject to a very high load from the probe rod when towing the helicopter. The force analysis was performed on the dynamic system consisting of Helicopter-ERSD-Ship to determine the maximum thrust force required by EMPU and ERSD or the maximum lateral and longitudinal external load on the claw.

As shown in Figure 12, the Cartesian coordinate system is established. Assume that the deck rolls to the negative $X$-axis direction, while the maximum lateral acceleration acts along the negative $X$-axis direction, and pitches to the negative direction of the $Y$-axis, while the maximum longitudinal acceleration acts along the negative direction of the $Y$-axis. The maximum vertical acceleration acts in the positive direction of the $\mathrm{Z}$-axis.
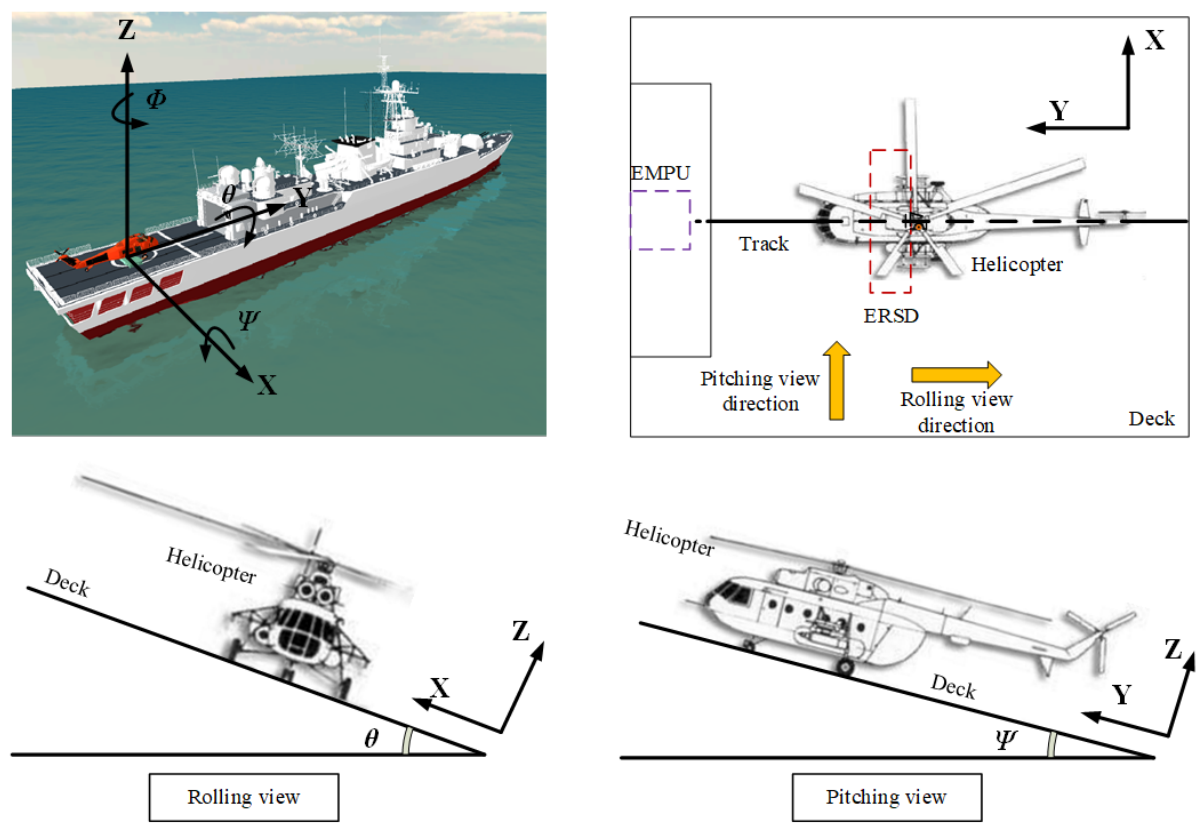

Figure 12. Schematic diagram of rolling and pitching of the deck. 
As shown in Figure 13, assume that the center of mass of the helicopter $\left(W_{\mathrm{H}}\right)$, the force point of the claw $(E)$, and the action center of the wind force $\left(W_{\mathrm{W}}\right)$ are all located on the central axis of the helicopter. Suppose that the ground points of the three tires of the helicopter are 1,2, and 3, and the rolling friction coefficient is $f$.

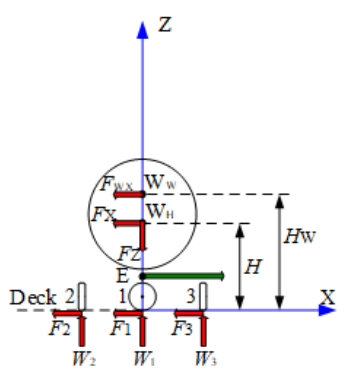

Force analysis during rolling
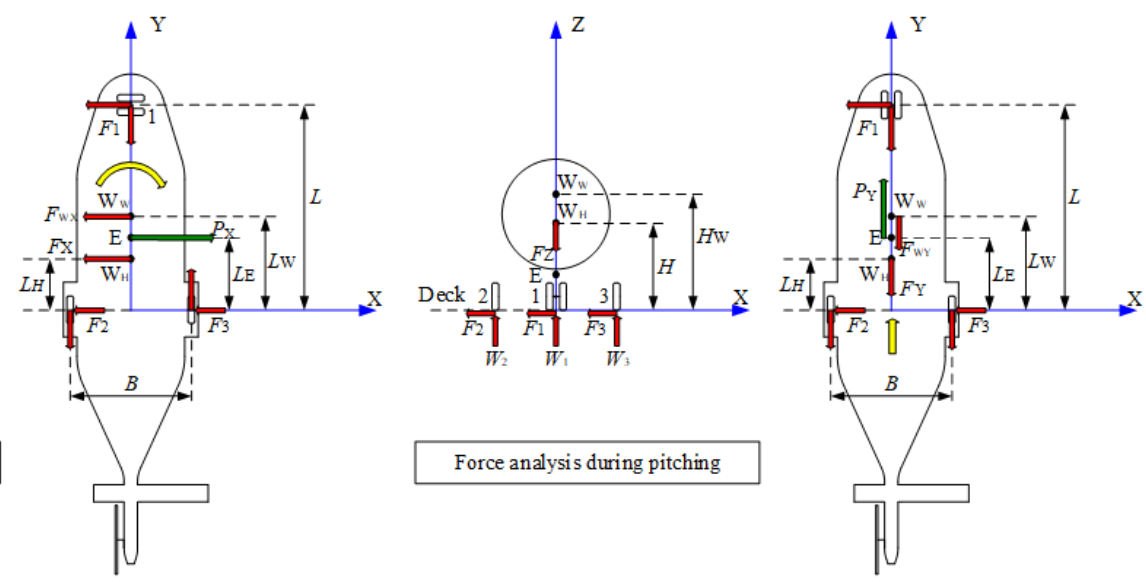

Figure 13. Force analysis of the helicopter.

Through simple force analysis, the following conclusions can be drawn.

1. In Figure 13, lateral resistance is maximum when the following three conditions are met:

- The card-axis of the front wheel is deflected by $90^{\circ}$;

- The wind is blowing along the negative direction of the $X$-axis;

- The claw pushes the helicopter in the direction of the yellow arrow.

Assume that the thrust force required by the claw is $P_{\mathrm{X}}$.

2. In Figure 13, the longitudinal resistance is maximum when the following three conditions are met:

- $\quad$ The card-axis of the front wheel is deflected $0^{\circ}$;

- The wind is blowing along the negative direction of the $Y$-axis;

- The claw pushes the helicopter forward in the direction of the yellow arrow.

- Assume that the thrust force required by the claw is $P_{\mathrm{Y}}$.

In Figure 13, let the roll angle be $\theta$, and the force acting on the center of mass is

$$
\left\{\begin{array}{l}
F_{X}=M_{H}\left(a_{x}+g \sin \theta\right) \\
F_{Z}=M_{H}\left(a_{z}+g \cos \theta\right)
\end{array} .\right.
$$

The rolling resistance of the front wheel is

$$
F_{1 X}=W_{1} f=\frac{F_{Z} L_{\mathrm{H}}}{L} f .
$$

The rolling resistance of the rear wheel is

$$
F_{2 Y}+F_{3 Y}=\left(W_{2}+W_{3}\right) f=\left(F_{Z}-W_{1}\right) f .
$$

The wind force on the helicopter is

$$
F_{\mathrm{WX}}=\frac{1}{2} \rho A_{X} C_{\mathrm{W}} v_{\mathrm{W}}^{2} .
$$


If we take the torque equilibrium on the Z-axis, we can get

$$
P_{X}=\frac{2\left(F_{\mathrm{WX}} L_{\mathrm{W}}+F_{X} L_{\mathrm{H}}+F_{1 X} L\right)+\left(F_{2 Y}+F_{3 Y}\right) B}{2 L_{\mathrm{E}}} .
$$

In Figure 13, let the pitch angle be $\lambda$, and the force acting on the center of mass is

$$
\left\{\begin{array}{l}
F_{Y}=M_{H}\left(a_{Y}+g \sin \lambda\right) \\
F_{Z}=M_{H}\left(a_{Z}+g \cos \lambda\right)
\end{array} .\right.
$$

The sum of the rolling resistance of the front and rear wheels is

$$
F_{1 Y}+F_{2 Y}+F_{3 Y}=\left(W_{1}+W_{2}+W_{3}\right) f=F_{Z} f .
$$

The wind force on the helicopter is

$$
F_{\mathrm{WY}}=\frac{1}{2} \rho A_{\mathrm{Y}} C_{\mathrm{W}} v_{\mathrm{W}}^{2}
$$

If we take the force equilibrium on the $Y$-axis, we can get

$$
P_{Y}=F_{W Y}+F_{Y}+\left(F_{1 Y}+F_{2 Y}+F_{3 Y}\right) .
$$

The parameters of a specific type of helicopter and ship are shown in Table 1, in level-3

\begin{tabular}{|c|c|c|c|c|c|}
\hline Parameters & Symbol & Value & Parameters & Symbol & Value \\
\hline $\begin{array}{l}\text { Distance between the mass } \\
\text { center and the } Z \text {-axis }\end{array}$ & $L_{\mathrm{H}}$ & $0.9 \mathrm{~m}$ & Helicopter mass & $M_{\mathrm{H}}$ & $10,000 \mathrm{~kg}$ \\
\hline $\begin{array}{l}\text { Distance between the force } \\
\text { point and the } Z \text {-axis }\end{array}$ & $L_{\mathrm{E}}$ & $0.9 \mathrm{~m}$ & $\begin{array}{l}\text { Distance between the front } \\
\text { wheel and rear } \\
\text { wheel centerline }\end{array}$ & $L$ & $7 \mathrm{~m}$ \\
\hline $\begin{array}{l}\text { Distance between the two } \\
\text { rear wheels }\end{array}$ & $B$ & $3.5 \mathrm{~m}$ & $\begin{array}{l}\text { Height from the mass center } \\
\text { to the deck }\end{array}$ & $H$ & $2 \mathrm{~m}$ \\
\hline $\begin{array}{l}\text { Distance from the wind } \\
\text { center to the } Z \text {-axis }\end{array}$ & $L_{\mathrm{W}}$ & $0.9 \mathrm{~m}$ & $\begin{array}{l}\text { Height from the wind center } \\
\text { to the deck }\end{array}$ & $H_{\mathrm{W}}$ & $1.3 \mathrm{~m}$ \\
\hline Lateral wind action constant & $A_{X} C_{W}$ & 20 & $\begin{array}{l}\text { Longitudinal wind force } \\
\text { action constant }\end{array}$ & $A_{Y} C_{W}$ & 2.5 \\
\hline Air density & $\rho$ & $1.29 \mathrm{~kg} / \mathrm{m}^{3}$ & Rolling friction coefficient & $f$ & 0.02 \\
\hline Maximum roll angle & $\theta$ & $10^{\circ}$ & Maximum pitch angle & $\lambda$ & $2.5^{\circ}$ \\
\hline $\begin{array}{c}\text { Maximum } \\
\text { lateral acceleration }\end{array}$ & $a_{\mathrm{x}}$ & $1 \mathrm{~m} / \mathrm{s}^{2}$ & $\begin{array}{c}\text { Maximum } \\
\text { longitudinal acceleration }\end{array}$ & $a_{\mathrm{y}}$ & $1 \mathrm{~m} / \mathrm{s}^{2}$ \\
\hline $\begin{array}{c}\text { Maximum } \\
\text { vertical acceleration }\end{array}$ & $a_{\mathrm{z}}$ & $0.5 \mathrm{~m} / \mathrm{s}^{2}$ & Maximum wind speed & $v_{\mathrm{W}}$ & $12 \mathrm{~m} / \mathrm{s}$ \\
\hline
\end{tabular}
sea conditions. Taking the data in Table 1 into Equations (18) and (22), it can be calculated that the maximum lateral and longitudinal load of the claw in level-3 sea conditions are $P_{X}=34,543 \mathrm{~N}$ and $P_{Y}=11,789 \mathrm{~N}$.

Table 1. Parameters of the helicopter and deck.

\section{System Modeling and Simulation}

\subsection{System Modeling of Capture Condition}

The capture task of EASIST can be divided into longitudinal and lateral capture, which are undertaken by EMPU and ERSD, respectively. Taking EMPU as an example, according to the power bond graph theory, the energy transfer of the transmission system can be described as the following process: 
1. The driving torque of the asynchronous motor (Potential Source) drives the reducer to rotate (Inertia Element and Resistive Element).

2. The reducer (Converter) drives the steel cable reel to rotate (Inertia Element and Resistive Element).

3. The steel cable reel transforms rotational motion to straight motion by the steel cable (Converter) and the chain (Converter).

4. The steel cable (Inertia Element and Resistive Element) drives ERSD and power cable (Inertia Element and Resistive Element) to move quickly. In contrast, the chain (Inertia Element and Resistive Element) drives the power cable reel to rotate (Converter, Inertia Element, and Resistive Element).

5. The chain and steel cable length varies with the tensile force (Capacitive Element).

The power bond graph model of the longitudinal capture system can be built according to the above descriptions, as shown in Figure 14, and the related bond graph was augmented and simplified. Similarly, the bond graph model of the lateral capture system can be obtained, as shown in Figure 15.

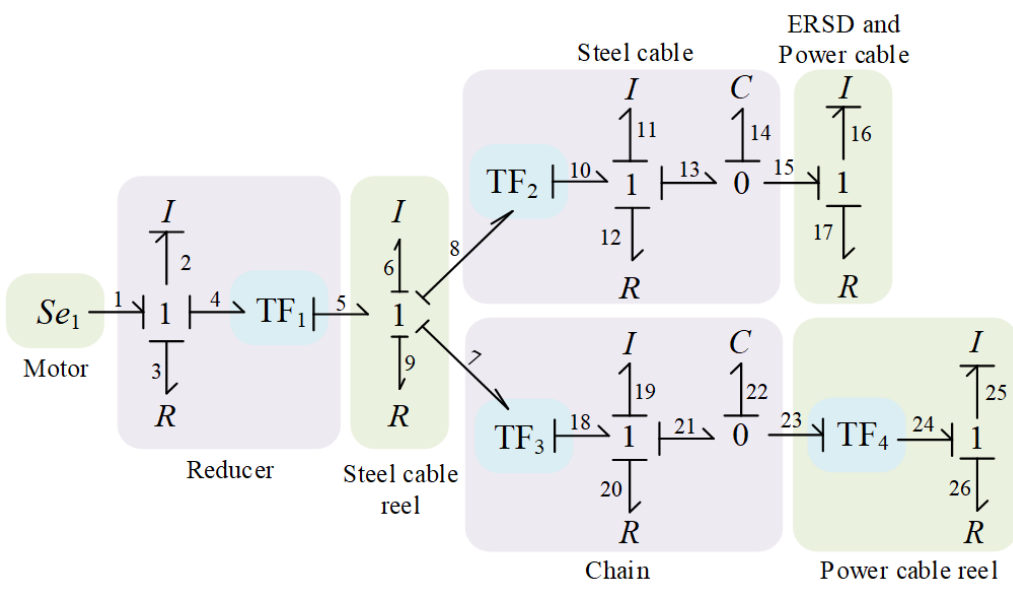

Figure 14. The bond graph of the longitudinal capture system.

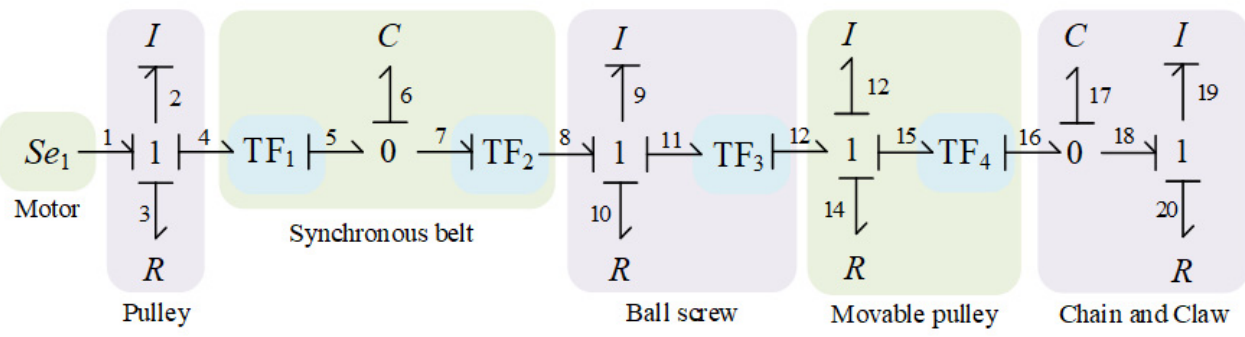

Figure 15. The bond graph of the lateral capture system.

For EMPU, take the state equation as follows:

$$
X_{1}^{\prime}=A_{1} \cdot X_{1}+B_{1} \cdot U_{1}
$$

The generalized momentum $p_{2}, p_{16}, p_{25}$, and generalized displacement $q_{14}, q_{22}$ corresponding to $I_{2}, I_{16}, I_{25}, C_{14}, C_{22}$ are selected as the state variables of the system, which is shown as follows:

$$
X_{1}=\left[\begin{array}{lllll}
p_{2} & q_{14} & p_{16} & q_{22} & p_{25}
\end{array}\right]^{\mathrm{T}} .
$$

The input of the system is the output torque of the motor, which is shown as follows:

$$
U_{1}=\left[S e_{1}\right]
$$


The characteristic equation of Resistive Element $R_{3}, R_{7}, R_{12}, R_{17}, R_{20}$, and $R_{26}$ is shown as follows:

$$
\left\{\begin{array}{l}
e_{3}=R_{3} \cdot f_{3} \\
e_{7}=R_{7} \cdot f_{7} \\
e_{12}=R_{12} \cdot f_{12} \\
e_{17}=R_{17} \cdot f_{17} \\
e_{20}=R_{20} \cdot f_{20} \\
e_{26}=R_{26} \cdot f_{26}
\end{array} .\right.
$$

The characteristic equation of Inertia Element and Capacitive Element $I_{2}, C_{14}, I_{16}, C_{22}$, and $I_{25}$ is shown as follows:

$$
\left\{\begin{array}{l}
f_{2}=\frac{1}{I_{2}} p_{2} \\
e_{14}=\frac{1}{C_{14}} q_{14} \\
f_{16}=\frac{1}{I_{16}} p_{16} \\
e_{22}=\frac{1}{C_{22}} q_{22} \\
f_{25}=\frac{1}{I_{25}} p_{25}
\end{array} .\right.
$$

The characteristic equation of Inertial Elements $I_{6}, I_{11}$, and $I_{19}$ with differential causality is shown as follows:

$$
\left\{\begin{array}{l}
e_{6}=I_{6} \cdot f_{6}^{\prime} \\
e_{11}=I_{11} \cdot f_{11}^{\prime} \\
e_{19}=I_{19} \cdot f_{19}^{\prime}
\end{array} .\right.
$$

The characteristic equations of Converter $T F_{1}, T F_{2}, T F_{3}$, and $T F_{4}$ are shown as follows:

$$
\begin{aligned}
& \left\{\begin{array}{l}
e_{4}=\frac{1}{m_{1}} \cdot e_{5} \\
f_{5}=\frac{1}{m_{1}} \cdot f_{4}
\end{array},\right. \\
& \left\{\begin{array}{l}
e_{8}=\frac{1}{m_{2}} \cdot e_{10} \\
f_{10}=\frac{1}{m_{2}} \cdot f_{8}
\end{array},\right. \\
& \left\{\begin{array}{l}
e_{9}=\frac{1}{m_{3}} \cdot e_{18} \\
f_{18}=\frac{1}{m_{3}} \cdot f_{9}
\end{array},\right. \\
& \left\{\begin{array}{l}
e_{24}=m_{4} \cdot e_{23} \\
f_{23}=m_{4} \cdot f_{24}
\end{array} .\right.
\end{aligned}
$$

The characteristic equations of 0 Knot and 1 Knot are shown as follows:

$$
\begin{gathered}
\left\{\begin{array}{l}
e_{2}=S e_{1}-e_{3}-e_{4}, \\
f_{1}=f_{2}=f_{3}=f_{4},
\end{array}\right. \\
\left\{\begin{array}{l}
e_{5}=e_{6}+e_{7}+e_{8}+e_{9} \\
f_{5}=f_{6}=f_{7}=f_{8}=f_{9}
\end{array},\right. \\
\left\{\begin{array}{l}
e_{10}=e_{11}+e_{12}+e_{13} \\
f_{10}=f_{11}=f_{12}=f_{13},
\end{array}\right. \\
\left\{\begin{array}{l}
e_{13}=e_{14}=e_{15}, \\
f_{14}=f_{13}-f_{15}
\end{array},\right. \\
\left\{\begin{array}{l}
e_{15}=e_{16}+e_{17} \\
f_{15}=f_{16}=f_{17},
\end{array}\right. \\
\left\{\begin{array}{l}
e_{18}=e_{19}+e_{20}+e_{21} \\
f_{18}=f_{19}=f_{20}=f_{21},
\end{array}\right. \\
\left\{\begin{array}{l}
e_{21}=e_{22}=e_{23}, \\
f_{22}=f_{21}-f_{23},
\end{array}\right.
\end{gathered}
$$




$$
\left\{\begin{array}{l}
e_{24}=e_{25}+e_{26} \\
f_{24}=f_{25}=f_{26}
\end{array} .\right.
$$

By sorting out and simplifying the above equations, the state equation of the system can be obtained, which is shown as follows:

$$
\left\{\begin{array}{l}
p_{2}^{\prime}=\frac{m_{1}^{2} m_{2} m_{3} I_{2}}{E} S e_{1}-\frac{m_{1}^{2} m_{2} m_{3} R_{3}+m_{3} R_{12}+m_{2} R_{20}}{E} p_{2}-\frac{m_{1} m_{2} m_{3} I_{2}}{C_{14} E} q_{14}-\frac{m_{1} m_{2} m_{3} I_{2}}{C_{22} E} q_{22} \\
q_{14}^{\prime}=\frac{1}{m_{1} m_{2} I_{2}} p_{2}-\frac{1}{I_{16}} p_{16} \\
p_{16}^{\prime}=\frac{1}{C_{14}} q_{14}-\frac{R_{17}}{I_{16}} p_{16} \\
q_{22}^{\prime}=\frac{1}{m_{1} m_{3} I_{2}} p_{2}-\frac{m_{4}}{I_{25}} p_{25} \\
p_{25}^{\prime}=\frac{m_{4}}{C_{22}} q_{22}-\frac{R_{26}}{I_{25}} p_{25}
\end{array}\right.
$$

where $E=m_{1}^{2} m_{2} m_{3} I_{2}+m_{2} m_{3} I_{6}+m_{2} m_{3} R_{7}+m_{3} I_{11}+m_{2} I_{19}$.

From the above equation, constant-coefficient matrix $A_{1}$ and control matrix $B_{1}$ can be obtained in the following form:

$$
\begin{gathered}
A_{1}=\left[\begin{array}{ccccc}
-\frac{m_{1}^{2} m_{2} m_{3} R_{3}+m_{3} R_{12}+m_{2} R_{20}}{E} & -\frac{m_{1} m_{2} m_{3} I_{2}}{C_{14} E} & 0 & -\frac{m_{1} m_{2} m_{3} I_{2}}{C_{22} E} & 0 \\
\frac{1}{m_{1} m_{2} I_{2}} & 0 & -\frac{1}{I_{16}} & 0 & 0 \\
0 & \frac{1}{C_{14}} & -\frac{R_{17}}{I_{16}} & 0 & 0 \\
\frac{1}{m_{1} m_{3} I_{2}} & 0 & 0 & 0 & -\frac{m_{4}}{I_{25}} \\
0 & 0 & 0 & \frac{m_{4}}{C_{22}} & -\frac{R_{26}}{I_{25}}
\end{array}\right] \\
B_{1}=\left[\begin{array}{ccccc}
\frac{m_{1}^{2} m_{2} m_{3} I_{2}}{E} & 0 & 0 & 0 & 0
\end{array}\right]^{T}
\end{gathered}
$$

In the same way, for ERSD, take the state equation as follows:

$$
X_{2}^{\prime}=A_{2} \cdot X_{2}+B_{2} \cdot U_{2} .
$$

The equation of system state variables is shown as follows:

$$
X_{2}=\left[\begin{array}{lllll}
p_{2} & q_{6} & p_{9} & q_{17} & p_{19}
\end{array}\right]^{\mathrm{T}} .
$$

The equation of system input is shown as follows:

$$
U_{2}=\left[S e_{1}\right] .
$$

The constant-coefficient matrix $A_{2}$ and control matrix $B_{2}$ of the system are shown as follows:

$$
\begin{gathered}
A_{2}=\left[\begin{array}{ccccc}
-\frac{R_{3}}{I_{2}} & -\frac{1}{m_{1} C_{6}} & 0 & 0 & 0 \\
\frac{1}{m_{1} I_{2}} & 0 & -\frac{m_{2}}{I_{9}} & 0 & 0 \\
0 & \frac{m_{2} m_{3}^{2} I_{9}}{C_{6}\left(m_{3}^{2} I_{9}+I_{13}\right)} & -\frac{m_{3}^{2} R_{10}+R_{14}}{m_{3}^{2} I_{9}+I_{13}} & -\frac{m_{3} I_{9}}{m_{4} C_{17}\left(m_{3}^{2} I_{9}+I_{13}\right)} & 0 \\
0 & 0 & \frac{1}{m_{3} m_{4} I_{9}} & 0 & -\frac{1}{I_{19}} \\
0 & 0 & 0 & \frac{1}{C_{17}} & -\frac{R_{20}}{I_{19}}
\end{array}\right] \\
B_{2}=\left[\begin{array}{ccccc}
1 & 0 & 0 & 0 & 0
\end{array}\right]^{\mathrm{T}}
\end{gathered}
$$

\subsection{System Modeling of Traction Condition}

It can also be divided into the longitudinal and lateral traction performed by EMPU and ERSD, respectively, when EASIST performs the traction task. Unlike the capture mode, 
EMPU and ERSD are affected by the motion resistance from the helicopter. Taking EMPU pulling the helicopter along the negative direction of the $Y$-axis as an example, the bond graph model is shown in Figure 16. And the bond graph model of ERSD laterally towing the helicopter is shown in Figure 17.

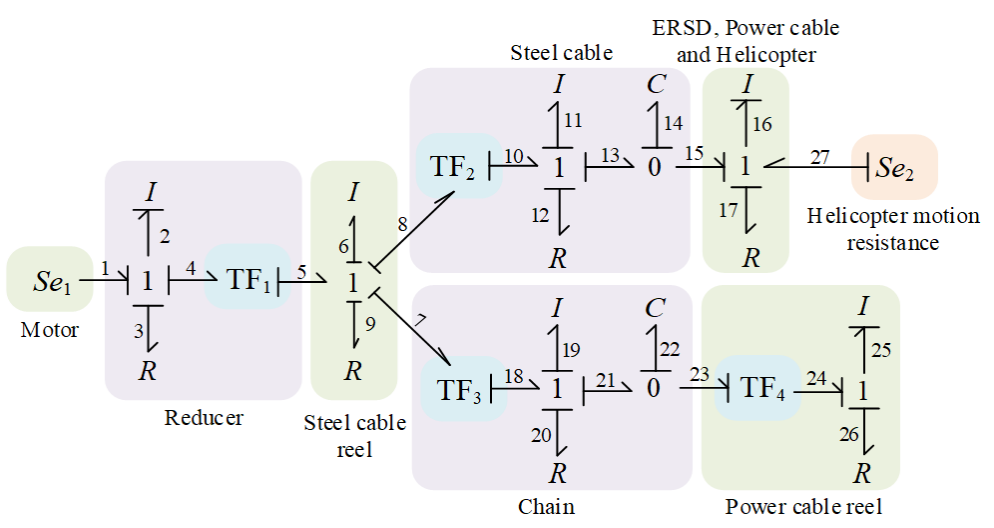

Figure 16. The bond graph of the longitudinal traction system.

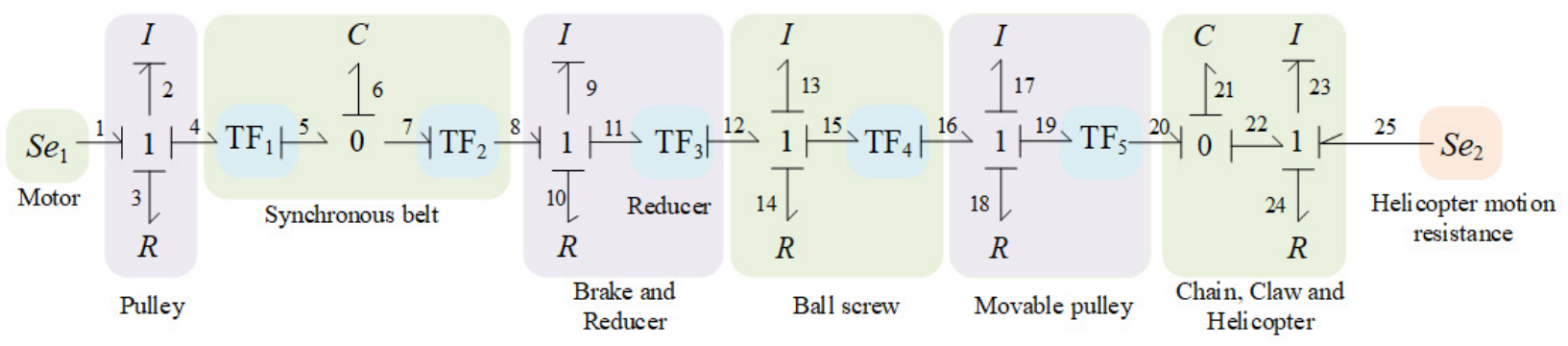

Figure 17. The bond graph of the lateral traction system.

In the same way, for EMPU, take the state equation as follows:

$$
X_{3}^{\prime}=A_{3} \cdot X_{3}+B_{3} \cdot U_{3} .
$$

The equation of system state variables is shown as follows:

$$
X_{3}=\left[\begin{array}{lllll}
p_{2} & q_{14} & p_{16} & q_{22} & p_{25}
\end{array}\right]^{\mathrm{T}} .
$$

The equation of system input is shown as follows:

$$
U_{3}=\left[\begin{array}{ll}
S e_{1} & S e_{2}
\end{array}\right]
$$

The constant-coefficient matrix $A_{3}$ and control matrix $B_{3}$ of the system are shown as follows:

$$
A_{3}=\left[\begin{array}{ccccc}
-\frac{m_{1}^{2} m_{2} m_{3} R_{3}+m_{3} R_{12}+m_{2} R_{20}}{E} & -\frac{m_{1} m_{2} m_{3} I_{2}}{C_{14} E} & 0 & -\frac{m_{1} m_{2} m_{3} I_{2}}{C_{22} E} & 0 \\
\frac{1}{m_{1} m_{2} I_{2}} & 0 & -\frac{1}{I_{16}} & 0 & 0 \\
0 & \frac{1}{C_{14}} & -\frac{R_{17}}{I_{16}} & 0 & 0 \\
\frac{1}{m_{1} m_{3} I_{2}} & 0 & 0 & 0 & -\frac{m_{4}}{2_{25}} \\
0 & 0 & 0 & \frac{m_{4}}{C_{22}} & -\frac{R_{26}}{I_{25}}
\end{array}\right],
$$




$$
B_{3}=\left[\begin{array}{cc}
\frac{m_{1}^{2} m_{2} m_{3} I_{2}}{E} & 0 \\
0 & 0 \\
0 & -1 \\
0 & 0 \\
0 & 0
\end{array}\right] .
$$

where $E=m_{1}^{2} m_{2} m_{3} I_{2}+m_{2} m_{3} I_{6}+m_{2} m_{3} R_{7}+m_{3} I_{11}+m_{2} I_{19}$.

For ERSD, take the state equation as follows:

$$
X_{4}^{\prime}=A_{4} \cdot X_{4}+B_{4} \cdot U_{4} .
$$

The equation of system state variables is shown as follows:

$$
X_{4}=\left[\begin{array}{lllll}
p_{2} & q_{6} & p_{9} & q_{21} & p_{23}
\end{array}\right]^{\mathrm{T}} .
$$

The equation of system input is shown as follows:

$$
U_{4}=\left[\begin{array}{ll}
S e_{1} & S e_{2}
\end{array}\right] .
$$

The constant-coefficient matrix $A_{2}$ and control matrix $B_{2}$ of the system are shown as follows:

$$
A_{4}=\left[\begin{array}{c}
-\frac{R_{3}}{I_{2}} \\
\frac{1}{m_{1} I_{2}} \\
0 \\
0 \\
0
\end{array}\right.
$$

$$
-\frac{1}{m_{1} C_{6}}
$$

0

$$
\frac{m_{2} m_{3}^{2} m_{4}^{2} I_{9}}{C_{6}\left(m_{3}^{2} m_{4}^{2} I_{9}+m_{4}^{2} I_{13}+I_{17}\right)}
$$

0

0

$$
\begin{gathered}
0 \\
-\frac{m_{2}}{I_{9}} \\
-\frac{R_{18}+m_{4}^{2} R_{14}+m_{3}^{2} m_{4}^{2} R_{10}}{m_{3}^{2} m_{4}^{2} I_{9}+m_{4}^{2} I_{13}+I_{17}} \\
\frac{1}{m_{3} m_{4} m_{5} I_{9}} \\
0
\end{gathered}
$$

$\left.\begin{array}{cc}0 & 0 \\ 0 & 0 \\ -\frac{m_{3} m_{4} I_{9}}{m_{5} C_{21}\left(I_{17}+m_{3}^{2} m_{4}^{2} I_{9}+m_{4}^{2} I_{13}\right)} & 0 \\ 0 & -\frac{1}{I_{23}} \\ \frac{1}{C_{21}} & -\frac{R_{24}}{I_{23}}\end{array}\right]$

$-\frac{R_{24}}{I_{23}}$

$$
B_{4}=\left[\begin{array}{ll}
1 & 0 \\
0 & 0 \\
0 & 0 \\
0 & 0 \\
0 & 1
\end{array}\right]
$$

\subsection{System Simulation}

The simulation test is necessary to verify the feasibility of the scheme and the accuracy of the dynamic model. The system simulation model was built according to the structure shown in Figure 18, and the relevant parameters of the dynamics model are shown in Tables 2 and 3. The specific simulation test includes the following two parts.

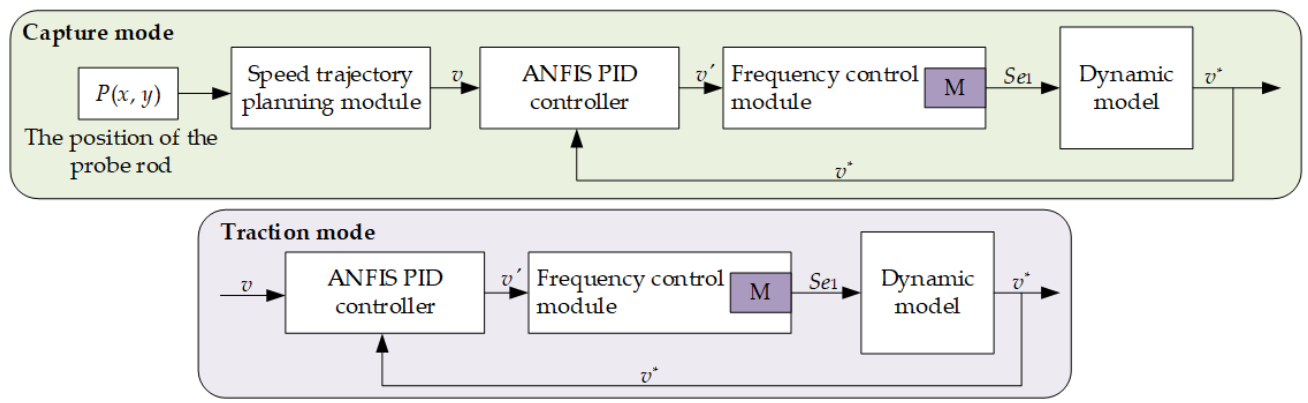

Figure 18. System simulation model. 
Table 2. Parameters of EMPU transmission system.

\begin{tabular}{|c|c|c|c|c|}
\hline Parts & Physical Meaning & Character & Value & Units \\
\hline Asynchronous motor & Driving torque & Potential Source & - & - \\
\hline \multirow{3}{*}{ Reducer } & The moment of inertia & Inertia Element & $5.7 \times 10^{-3}$ & $\mathrm{~kg} \cdot \mathrm{m}^{2}$ \\
\hline & Rotational damping & Resistive Element & $11.4 \times 10^{-4}$ & $\mathrm{~N} \cdot \mathrm{m} \cdot \mathrm{s} / \mathrm{rad}$ \\
\hline & Reduction ratio & Converter & 50 & - \\
\hline \multirow{2}{*}{ Steel cable reel } & The moment of inertia & Inertia Element & 1.721 & $\mathrm{~kg} \cdot \mathrm{m}^{2}$ \\
\hline & Rotational damping & Resistive Element & $7.9 \times 10^{-3}$ & $\mathrm{~N} \cdot \mathrm{m} \cdot \mathrm{s} / \mathrm{rad}$ \\
\hline \multirow{4}{*}{ Steel cable } & Rotational motion to Straight motion & Converter & $1 / 0.3$ & $\mathrm{rad} / \mathrm{m}$ \\
\hline & Mass & Inertia Element & 57 & $\mathrm{~kg}$ \\
\hline & Movement damping & Resistive Element & 18.12 & $\mathrm{~N} \cdot \mathrm{s} / \mathrm{m}$ \\
\hline & Elastic coefficient & Capacitive Element & $0.3 \times 10^{-10}$ & $\mathrm{~m} / \mathrm{N}$ \\
\hline \multirow{2}{*}{ ERSD and Power cable } & Mass & Inertia Element & 1500 & $\mathrm{~kg}$ \\
\hline & Movement damping & Resistive Element & 88.1 & $\mathrm{~N} \cdot \mathrm{s} / \mathrm{m}$ \\
\hline \multirow{4}{*}{ Chain } & Rotational motion to Straight motion & Converter & $1 /\left(72 \times 10^{-3}\right)$ & $\mathrm{rad} / \mathrm{m}$ \\
\hline & Mass & Inertia Element & 3.7 & $\mathrm{~kg}$ \\
\hline & Movement damping & Resistive Element & 11.7 & $\mathrm{~N} \cdot \mathrm{s} / \mathrm{m}$ \\
\hline & Elastic coefficient & Capacitive Element & $0.5 \times 10^{-7}$ & $\mathrm{~m} / \mathrm{N}$ \\
\hline \multirow{3}{*}{ Power cable reel } & Straight motion to rotational motion & Converter & $72 \times 10^{-3}$ & $\mathrm{~m} / \mathrm{rad}$ \\
\hline & The moment of inertia & Inertia Element & 21 & $\mathrm{~kg}$ \\
\hline & Rotational damping & Resistive Element & 7.4 & $\mathrm{~N} \cdot \mathrm{s} / \mathrm{m}$ \\
\hline \multirow{2}{*}{ Helicopter } & Motion resistance & Potential Source & - & - \\
\hline & Mass & Inertia Element & $10^{4}$ & $\mathrm{~kg}$ \\
\hline
\end{tabular}

Table 3. Parameters of ERSD transmission system.

\begin{tabular}{|c|c|c|c|c|}
\hline Parts & Physical Meaning & Character & Value & Units \\
\hline Asynchronous motor & Driving torque & Potential Source & - & - \\
\hline \multirow{2}{*}{ Pully } & The moment of inertia & Inertia Element & $1.04 \times 10^{-3}$ & $\mathrm{~kg} \cdot \mathrm{m}^{2}$ \\
\hline & Rotational damping & Resistive Element & $8.2 \times 10^{-4}$ & $\mathrm{~N} \cdot \mathrm{m} \cdot \mathrm{s} / \mathrm{rad}$ \\
\hline \multirow{3}{*}{ Synchronous belt } & Rotational motion to straight motion & Converter & $1 / 48.51 \times 10^{-3}$ & $\mathrm{rad} / \mathrm{m}$ \\
\hline & Elastic coefficient & Capacitive Element & $1 / 15,200$ & $\mathrm{~m} / \mathrm{N}$ \\
\hline & Straight motion to rotational motion & Converter & $48.51 \times 10^{-3}$ & $\mathrm{~m} / \mathrm{rad}$ \\
\hline \multirow{3}{*}{ Brake and Reducer } & The moment of inertia & Inertia Element & $3.865 \times 10^{-3}$ & $\mathrm{~kg} \cdot \mathrm{m}^{2}$ \\
\hline & Rotational damping & Resistive Element & $3.8 \times 10^{-3}$ & $\mathrm{~N} \cdot \mathrm{m} \cdot \mathrm{s} / \mathrm{rad}$ \\
\hline & The reduction ratio of reducer & Converter & 40 & - \\
\hline \multirow{3}{*}{ Ball screw } & The moment of inertia & Inertia Element & $2.295 \times 10^{-2}$ & $\mathrm{~kg} \cdot \mathrm{m}^{2}$ \\
\hline & Rotational damping & Resistive Element & $2.5 \times 10^{-3}$ & $\mathrm{~N} \cdot \mathrm{m} \cdot \mathrm{s} / \mathrm{rad}$ \\
\hline & Rotational motion to straight motion & Converter & $2 \pi /\left(20 \times 10^{-3}\right)$ & $\mathrm{rad} / \mathrm{m}$ \\
\hline \multirow{3}{*}{ Movable pulley } & Mass & Inertia Element & 35.753 & $\mathrm{~kg}$ \\
\hline & Movement damping & Resistive Element & 40 & $\mathrm{~N} \cdot \mathrm{s} / \mathrm{m}$ \\
\hline & Chain transmission ratio & Converter & $1 / 2$ & - \\
\hline \multirow{3}{*}{ Chain and Claw } & The elastic coefficient of chain & Capacitive Element & $0.5 \times 10^{-7}$ & $\mathrm{~m} / \mathrm{N}$ \\
\hline & Mass & Inertia Element & 44.328 & $\mathrm{~kg}$ \\
\hline & Movement damping & Resistive Element & 130 & $\mathrm{~N} \cdot \mathrm{s} / \mathrm{m}$ \\
\hline \multirow{2}{*}{ Helicopter } & Motion resistance & Potential Source & - & - \\
\hline & Mass & Inertia Element & $10^{4}$ & $\mathrm{~kg}$ \\
\hline
\end{tabular}


- Capture simulation: This test is used to verify whether the capture time meets the requirements and whether the final capture speed can be significantly reduced.

- Traction simulation: The purpose of this test is to verify whether EASIST can adjust the moving speed of the claw in real time according to the system input when performing the traction task.

\subsubsection{Capture Simulation}

To get the maximum capture time of EASIST, the probe rod is set at the limit position $P$ $(-2200,-1100)$. According to the system performance and the actual use requirements, the capture speed is set to $0.02 \mathrm{~m} / \mathrm{s}$, the maximum speed is set to $1.5 \mathrm{~m} / \mathrm{s}$, and the acceleration and deceleration are set to $0.3 \mathrm{~s}$. According to Equations (11)-(13), the speed trajectory planning of the claw can be carried out.

The simulation test was carried out according to the structure in Figure 18. The ANFIS, fuzzy, and PID controllers were used for the test. The velocity and displacement curve of the claw obtained by the simulation are shown in Figures 19 and 20.

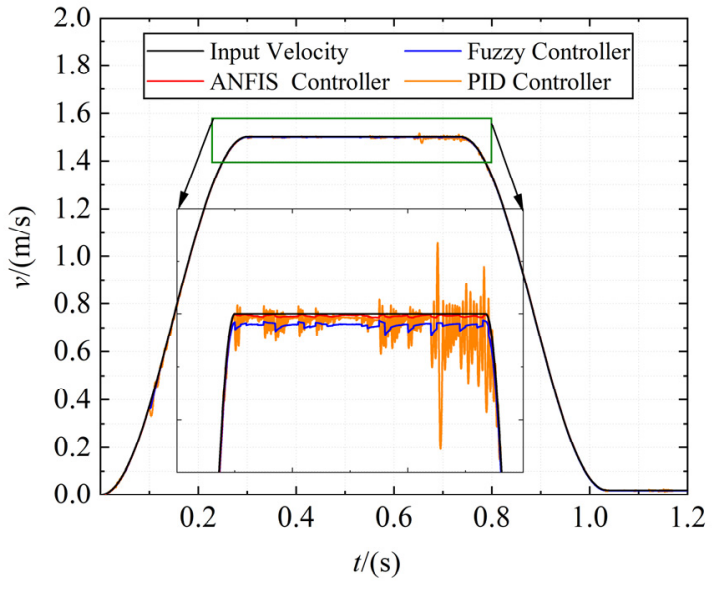

(a)

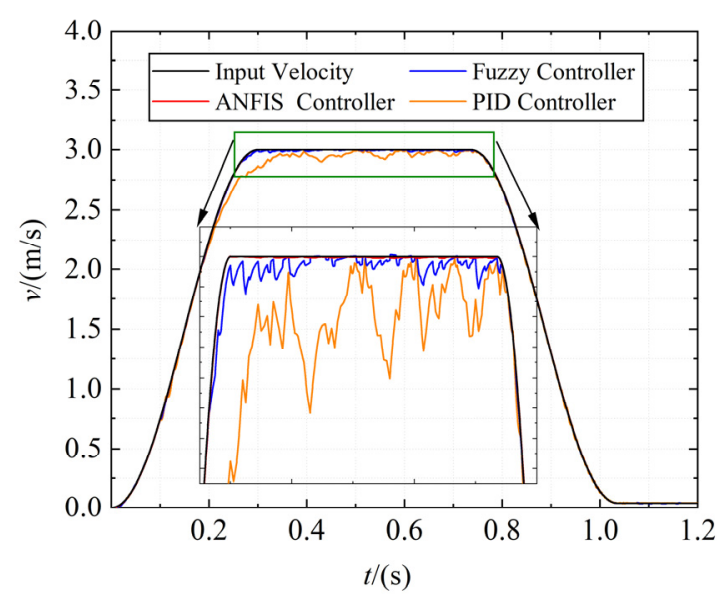

(b)

Figure 19. The capture velocity curve of the claw. (a) Longitudinal velocity curve; (b) Lateral velocity curve.

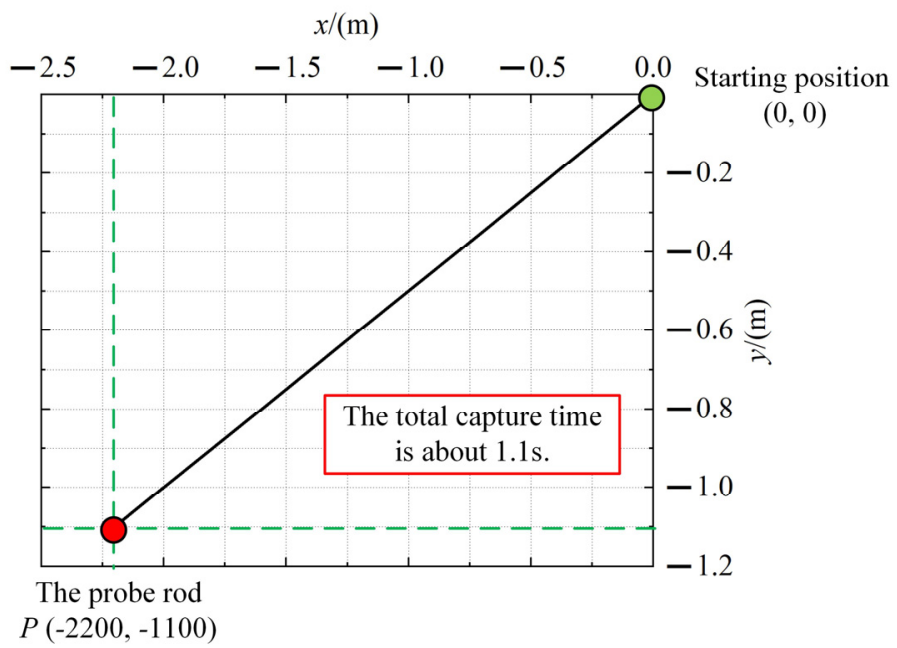

Figure 20. The displacement curve of the claw with the ANFIS controller.

As shown in Figure 19, EMPU and ERSD can achieve a good speed tracking effect in both acceleration and deceleration phases when executing the capture task. And the capture speed, which is about $0.02 \mathrm{~m} / \mathrm{s}$, can be significantly reduced. However, only the 
ANFIS controller can achieve a better control effect in the uniform motion phase. In contrast, both the fuzzy controller and PID controller have significant errors.

It can be seen from Figure 20 that the claw can move according to the predetermined trajectory under the action of the ANFIS controller. The maximum capture time is about $1.1 \mathrm{~s}$, which meets the requirements of EASIST.

\subsubsection{Traction Simulation}

The simulation test was carried out according to the structure in Figure 18. And the ANFIS, fuzzy, and PID controllers were used for the test.

The traction speed curve was set as a sinusoidal curve with a maximum of $0.04 \mathrm{~m} / \mathrm{s}$ and minimum of $0.02 \mathrm{~m} / \mathrm{s}$ and a period of $2 \mathrm{~s}$ according to the use requirements [6]. And the load curves of the claw were set as a sawtooth curve with a maximum of $12 \mathrm{kN}$ and $35 \mathrm{kN}$, according to the calculation results in Section 4.2, as shown in Figure 21. The load force period was set as half of the speed period to verify the anti-interference ability of the controller more effectively.

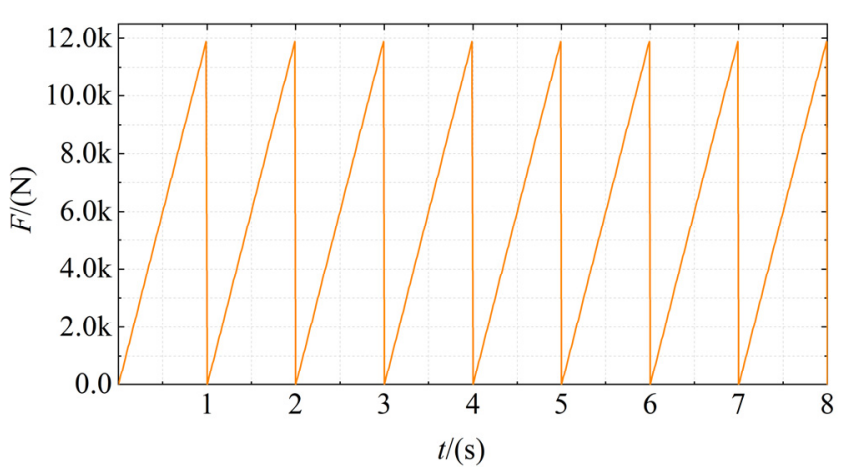

(a)

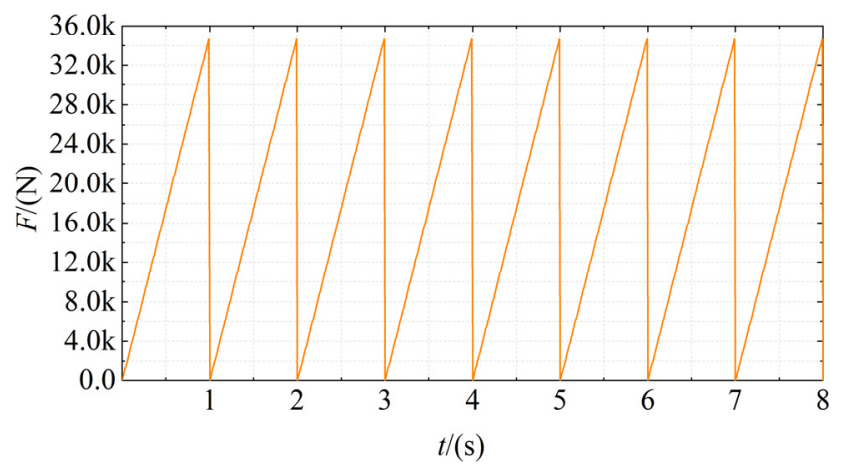

(b)

Figure 21. The load curves of the claw. (a) EMPU; (b) ERSD.

The longitudinal and lateral velocity tracking curves obtained by the simulations are shown in Figures 22 and 23.

As Figure 22 shows, EMPU can adjust the speed according to the system requirements under the maximum load of $12 \mathrm{kN}$. Moreover, only the ANFIS controller can achieve a better control effect, and the maximum error is only about $0.25-2 \%$, only half of the fuzzy controller.

As Figure 23 shows, ERSD can also adjust the speed under the maximum load of $35 \mathrm{kN}$. ANFIS also achieved a good control effect with an error of about $1-2 \%$, while both the fuzzy and PID controllers had significant errors.

Compared with Figure 22, the velocity curve in Figure 23 always has a minor fluctuation. This phenomenon is due to the chain drive in ERSD, while EMPU uses the cable drive. Tables 2 and 3 show that the chain has a more significant elastic coefficient than the steel cable. The phenomenon also indicates that the established dynamic model can accurately reflect the dynamic characteristics of the system. 


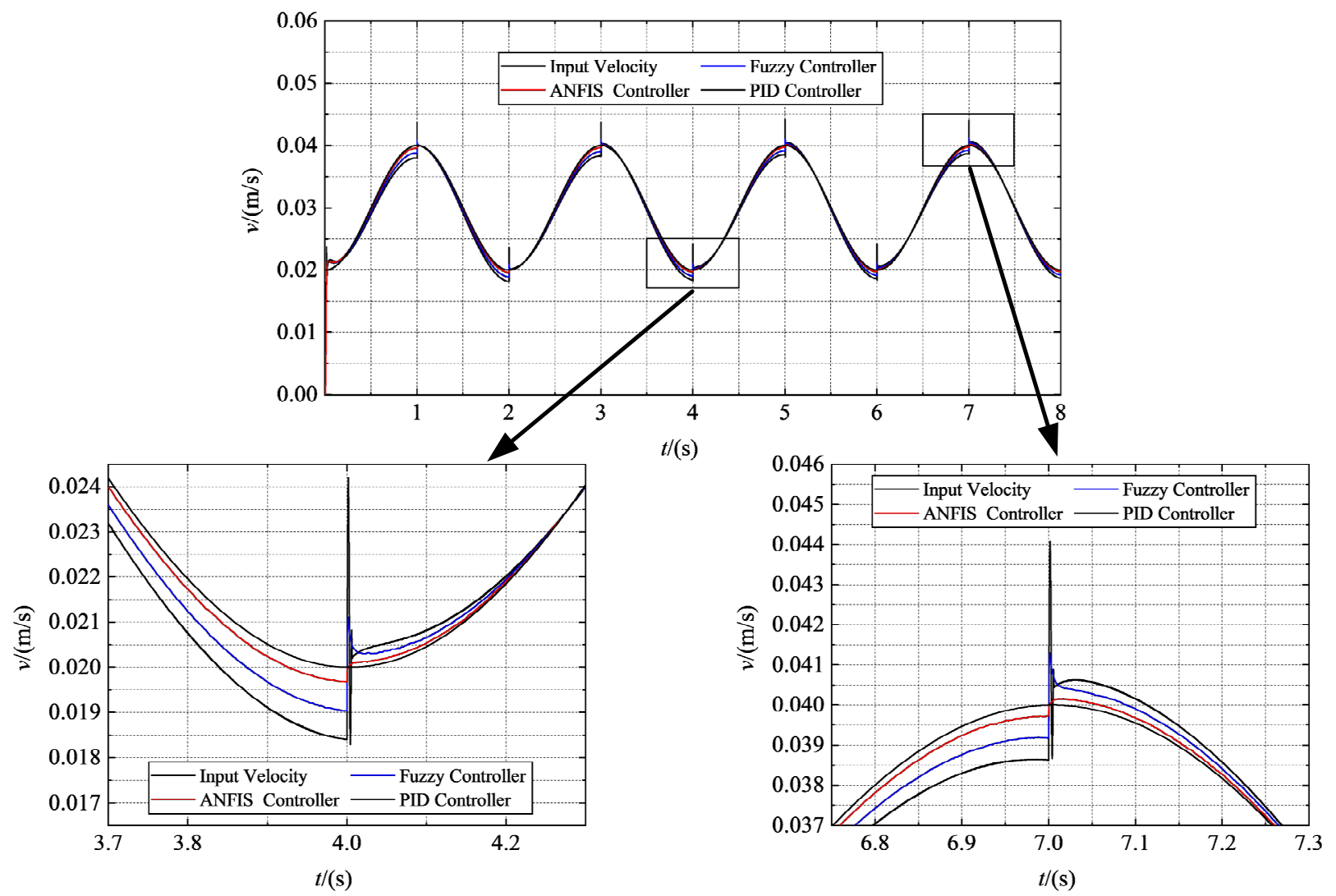

Figure 22. The traction velocity curve of the claw. (Longitudinal velocity curve).

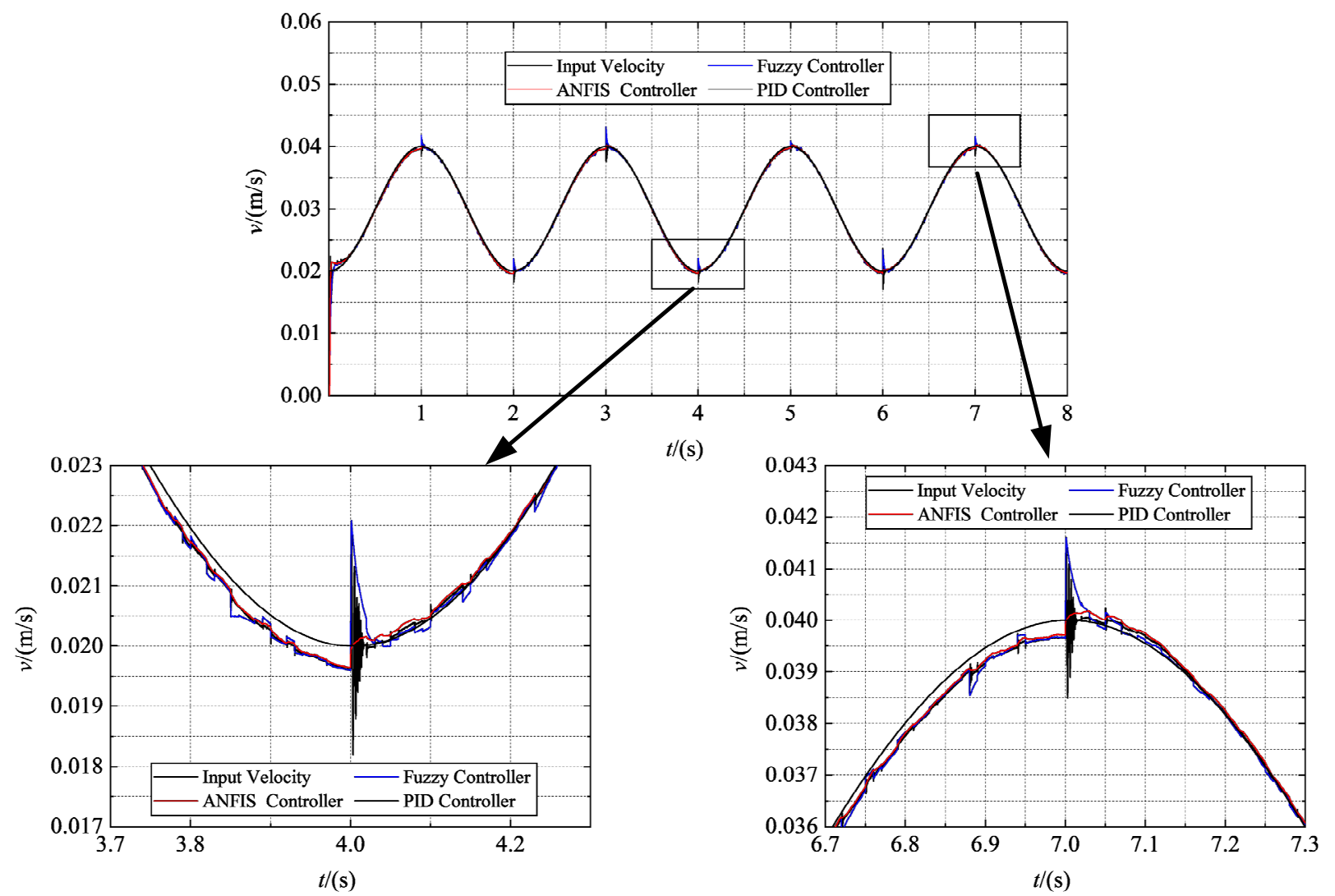

Figure 23. The traction velocity curve of the claw. (Lateral velocity curve). 


\section{Conclusions}

In this paper, the transmission system and the control system of EASIST were designed according to the working characteristics. The dynamics model of the system was established by power bond graph theory, and the simulation tests were carried out. According to the simulation results, the following conclusions can be drawn:

1. The dynamic model of the transmission system was established, and the simulation results show that the dynamic model can better describe the dynamic characteristics of the system $[46,47]$. This result provides a theoretical basis for subsequent production and processing.

2. A new capture scheme was designed. This scheme reduces the maximum capture time by about $60 \%$ while the original functional requirements remain unchanged. In addition, the capture speed is further limited, which can reduce the capture force significantly. This result will enable EASIST to be compatible with small shipborne aircraft.

3. Compared with the fuzzy and PID controller, the designed ANFIS controller has a better speed control effect. The ANFIS controller can achieve a superior speed tracking effect under the maximum loading force during the traction task. This result is of great significance for improving the traction efficiency of EASIST.

Author Contributions: Conceptualization, Z.Z. and Q.L.; methodology, Z.Z. and Q.L.; validation, Q.L. and L.W.; formal analysis, Q.L., D.Z. and T.J.; writing-original draft preparation, Q.L.; funding acquisition, Z.Z. and D.Z. All authors have read and agreed to the published version of the manuscript.

Funding: This research was funded by Hebei Provincial Department of Science and Technology, grant number 20353501D and 21351802D, and Ministry of Science and Technology of China, grant number 2016YFC0802902.

Institutional Review Board Statement: Not applicable.

Informed Consent Statement: Not applicable.

Conflicts of Interest: The authors declare no conflict of interest.

\section{References}

1. Taymourtash, N.; Zagaglia, D.; Zanotti, A.; Muscarello, V.; Gibertini, G.; Quaranta, G. Experimental study of a helicopter model in shipboard operations. Aerosp. Sci. Technol. 2021, 115, 106774. [CrossRef]

2. Guo, Y.; Wang, W.; Zhang, S.; Xu, W. Research on Attack Mode Selection of Helicopter Hovering and Forward for Dropping Torpedo in the Air. In Proceedings of the 2021 IEEE 6th International Conference on Computer and Communication Systems (ICCCS), Chengdu, China, 23-26 April 2021.

3. Zheng, J. A Test Method for Helicopter Landing Gear Load. Int. J. Mech. Eng. Appl. 2021, 9, 19. [CrossRef]

4. Su, D.; Xu, G.; Huang, S.; Shi, Y. Numerical investigation of rotor loads of a shipborne coaxial-rotor helicopter during a vertical landing based on moving overset mesh method. Eng. Appl. Comput. Fluid Mech. 2019, 13, 309-326. [CrossRef]

5. Tušl, M.; Rainieri, G.; Fraboni, F.; De Angelis, M.; de Polo, M.; Pietrantoni, L.; Pingitore, A. Helicopter Pilots' Tasks, Subjective Workload, and the Role of External Visual Cues During Shipboard Landing. J. Cogn. Eng. Decis. Mak. 2020, 14, 242-257. [CrossRef]

6. Zhang, Z.; Liu, Q.; Zhao, D.; Wang, L.; Yang, P. Research on Shipborne Helicopter Electric Rapid Secure Device: System De-sign, Modeling, and Simulation. Sensors 2022, 22, 1514. [CrossRef]

7. Lu, Y.; Chang, X.; Chuang, Z.; Xing, J.; Zhou, Z.; Zhang, X. Numerical investigation of the unsteady coupling airflow impact of a full-scale warship with a helicopter during shipboard landing. Eng. Appl. Comput. Fluid Mech. 2020, 14, 954-979. [CrossRef]

8. Greer, W.B.; Sultan, C. Infinite horizon model predictive control tracking application to helicopters. Aerosp. Sci. Technol. 2020, 98, 105675. [CrossRef]

9. Yu, X.; Yang, J.; Li, S. Disturbance observer-based autonomous landing control of unmanned helicopters on moving ship-board. Nonlinear Dyn. 2020, 102, 131-150. [CrossRef]

10. Owen, I.; Lee, R.; Wall, A.; Fernandez, N. The NATO generic destroyer-a shared geometry for collaborative research into modelling and simulation of shipboard helicopter launch and recovery. Ocean Eng. 2021, 228, 108428. [CrossRef]

11. Zhao, D.; Yang, H.; Yao, S.; Ni, T. Numerical investigation for coupled rotor/ship flowfield using two models based on the momentum source method. Eng. Appl. Comp. Fluid. 2021, 15, 1902-1918.

12. Shi, Y.; Li, G.; Su, D.; Xu, G. Numerical investigation on the ship/multi-helicopter dynamic interface. Aerosp. Sci. Technol. 2020, 106, 106175. [CrossRef]

13. Li, Y.; Zhang, Z.; Xiong, Z.; Xiao, J.; Li, G. Collision modeling method of ship-board helicopter landing. Syst. Eng. Electron. 2015, 430, 1691-1696. 
14. Zhao, D.; Yang, H.; Giuseppe, C.; Li, W.; Ni, T.; Yao, S. Modeling and analysis of landing collision dynamics for a shipborne helicopter. Front. Mech. Eng. 2021, 16, 151-162. [CrossRef]

15. Zhao, D.; Wang, Q.; Zhang, Z. Extenics theory for reliability assessment of carrier helicopter based on analytic hierarchy process. J. Jilin Univ. Eng. Technol. 2016, 46, 1528-1531.

16. Wang, Q.; Zhao, D.; Wei, H.; Zhao, Y. Study of the landing dynamics of carrier based helicopter under complex sea conditions. J. Northeast. Univ. Nat. Sci. 2017, 38, 1595-1600.

17. Wang, Q.; Zhao, D.; Zhao, Y.; Chen, N. Dynamic analysis of carrier helicopter on complex. J. Jilin Univ. Eng. Technol. 2017, 47, 1109-1113.

18. Sher, F.; Raore, D.; Klemeš, J.J.; Rafi-Ul-Shan, P.M.; Khzouz, M.; Marintseva, K.; Razmkhah, O. Unprecedented Impacts of Aviation Emissions on Global Environmental and Climate Change Scenario. Curr. Pollut. Rep. 2021, 7, 549-564. [CrossRef] [PubMed]

19. Sher, F.; Hazafa, A.; Marintseva, K.; Rasheed, T.; Ali, U.; Rashid, T.; Babu, A.; Khzouz, M. Fully solar powered Doncaster Sheffield Airport: Energy evaluation, glare analysis and CO2 mitigation. Sustain. Energy Technol. Assess. 2021, 45, 101122. [CrossRef]

20. Boukhalfa, G.; Belkacem, S.; Chikhi, A.; Benaggoune, S. Genetic algorithm and particle swarm optimization tuned fuzzy PID controller on direct torque control of dual star induction motor. J. Cent. South Univ. 2019, 26, 1886-1896. [CrossRef]

21. Qi, X.; Su, T.; Zhou, K.; Yang, J.C.; Gan, X.P.; Zhang, Y.C. Development of AC Motor Model Predictive Control Strategy: An Overview. Proc. CSEE 2021, 677, 6408-6419.

22. Sartorius, A.R.; de Jesus Moreno, J.; Pinon, O.; Ruiz, A.E. A new approach for adjusting scale factor in fuzzy PD+ I controllers with anti-windup. J. Intell. Fuzzy Syst. 2014, 27, 2319-2326. [CrossRef]

23. Arpaci, H.; Ozguven, O.F. Design of Adaptive Fractional-Order PID Controller to Enhance Robustness by Means of Adaptive Network Fuzzy Inference System. Int. J. Fuzzy Syst. 2017, 19, 1118-1131. [CrossRef]

24. Milovanović, M.B.; Antić, D.S.; Milojković, M.T.; Nikolić, S.S.; Perić, S.L.; Spasić, M.D. Adaptive PID control based on orthogonal endocrine neural networks. Neural Netw. 2016, 84, 80-90. [CrossRef] [PubMed]

25. Premkumar, K.; Manikandan, B. Adaptive Neuro-Fuzzy Inference System based speed controller for brushless DC motor. Neurocomputing 2014, 138, 260-270. [CrossRef]

26. Premkumar, K.; Manikandan, B. Fuzzy PID supervised online ANFIS based speed controller for brushless dc motor. Neurocomputing 2015, 157, 76-90. [CrossRef]

27. Navaneethakkannan, C.; Sudha, M. Analysis and Implementation of ANFIS-based Rotor Position Controller for BLDC Motors. J. Power Electron. 2016, 16, 564-571. [CrossRef]

28. Eski, I.; Yıldırım, Ş. Neural network-based fuzzy inference system for speed control of heavy duty vehicles with electronic throttle control system. Neural Comput. Appl. 2017, 28, 907-916. [CrossRef]

29. Wang, Y.; Zhao, D.; Wang, L.; Zhang, Z.; Wang, L.; Hu, Y. Dynamic simulation and analysis of the elevating mechanism of a forklift based on a power bond graph. J. Mech. Sci. Technol. 2016, 30, 4043-4048. [CrossRef]

30. Rodríguez-Guillén, J.; Salas-Cabrera, R.; García-Vite, P.M. Bond Graph as a formal methodology for obtaining a wind turbine drive train model in the per-unit system. Int. J. Electr. Power Energy Syst. 2021, 124, 106382. [CrossRef]

31. Karimian, S.; Jahanbin, Z. Bond graph modeling of a typical flapping wing micro-air-vehicle with the elastic articulated wings. Meccanica 2020, 55, 1263-1294. [CrossRef]

32. Badoud, A.E.; Merahi, F.; Bouamama, B.O.; Mekhilef, S. Bond graph modeling, design and experimental validation of a photovoltaic/fuel cell/ electrolyzer/battery hybrid power system. Int. J. Hydrogen Energy 2021, 46, 24011-24027. [CrossRef]

33. Song, K.; Wang, Y.; An, C.; Xu, H.; Ding, Y. Design and Validation of Energy Management Strategy for Extended-Range Fuel Cell Electric Vehicle Using Bond Graph Method. Energies 2021, 14, 380. [CrossRef]

34. Yahi, F.; Belhamel, M.; Bouzeffour, F.; Sari, O. Structured dynamic modeling and simulation of parabolic trough solar collector using bond graph approach. Sol. Energy 2020, 196, 27-38. [CrossRef]

35. Liu, W.; Li, L.; Cai, W.; Li, C.; Li, L.; Chen, X.; Sutherland, J.W. Dynamic characteristics and energy consumption modelling of machine tools based on bond graph theory. Energy 2020, 212, 118767. [CrossRef]

36. Mezghani, D.; Mami, A.; Dauphin-Tanguy, G. Bond graph modelling and control enhancement of an off-grid hybrid pumping system by frequency optimization. Int. J. Numer. Model. Electron. Netw. Devices Fields 2020, 33, e2717. [CrossRef]

37. Ghimire, P.; Zadeh, M.; Pedersen, E.; Thorstensen, J. Dynamic Modeling, Simulation, and Testing of a Marine DC Hybrid Power System. IEEE Trans. Transp. Electrif. 2021, 7, 905-919. [CrossRef]

38. Aftabi Talami, M.; Jamali, A.; Nariman-zadeh, N. A new method for extracting the state equations from bond graph of dynamical systems (SEBG method). Int. J. Gen. Syst. 2021, 50, 703-723. [CrossRef]

39. Schock, A.R. Development of a Planar Shipboard Skid-Equipped Rotary-Wing Aircraft Manoeuvring and Securing Simulation. Ph.D. Thesis, Carleton University, Ottawa, ON, Canada, 2020.

40. Li, B.; Wang, L.; Zhang, S.; Wang, J. Research on Loop Decoupling Control Based on Fuzzy RBF Neural Network. In Proceedings of the 2021 33rd Chinese Control and Decision Conference (CCDC), Kunming, China, 22-24 May 2021.

41. Sher, F.; Chen, S.; Raza, A.; Rasheed, T.; Razmkhah, O.; Rashid, T.; Rafi-Ul-Shan, P.M.; Erten, B. Novel strategies to reduce engine emissions and improve energy efficiency in hybrid vehicles. Clean. Eng. Technol. 2021, 2, 100074. [CrossRef]

42. Liu, Q.; Zhang, Z.; Zhao, D.; Wang, L.; Meng, F.; Liu, C. Research on Speed Tracking of Asynchronous Motor Based on Fuzzy Control and Vector Control. In Proceedings of the 2020 39th Chinese Control Conference (CCC), Shenyang, China, 27-29 July 2020. 
43. Kan, C.; Bao, X.; Wang, X.; Xiong, F.; Ma, B. Overview and Recent developments of Brushless Doubly-fed Machines. Proc. CSEE 2018, 38, 3939-3959.

44. Wang, L.; Lin, L.; Chang, Y.; Xue, F. Velocity Planning Algorithm in One-Dimensional Linear Motion for Astronaut Virtual Training. J. Astronaut. 2021, 42, 1600-1609.

45. Li, Z.; Wang, T.; Wang, B.; Guo, Z.; Chen, D. Trajectory planning for manipulator in Cartesian space based on constrained S-curve velocity. CAAI T. Intell. Sys. 2019, 14, 655-661.

46. Hussain, S.Z.; Kausar, Z.; Koreshi, Z.U.; Sheikh, S.R.; Rehman, H.Z.U.; Yaqoob, H.; Shah, M.F.; Abdullah, A.; Sher, F. Feed-back Control of Melt Pool Area in Selective Laser Melting Additive Manufacturing Process. Processes 2021, 9, 1547. [CrossRef]

47. Rashid, T.; Taqvi, S.A.A.; Sher, F.; Rubab, S.; Thanabalan, M.; Bilal, M.; Islam, B.U. Enhanced lignin extraction and optimisation from oil palm biomass using neural network modelling. Fuel 2021, 293, 120485. [CrossRef] 